\title{
Cross-linked beta alumina nanowires with compact gel polymer electrolyte coating for ultra-stable sodium metal battery
}

Danni Lei, ${ }^{1}$, Yan-Bing He ${ }^{1}$, Huijuan Huang ${ }^{3}$, Yifei Yuan (1) ${ }^{4}$, Guiming Zhong ${ }^{5}$, Qiang Zhao ${ }^{1}$, Xiaoge Hao ${ }^{1}$,

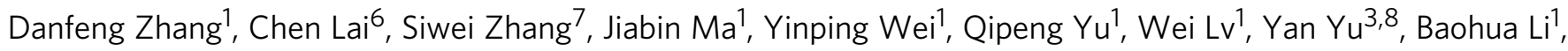
Quan-Hong Yang ${ }^{9}$, Yong Yang (10 ${ }^{10}$, Jun Lu id ${ }^{4}$ \& Feiyu Kang ${ }^{1,7}$

Sodium metal batteries have potentially high energy densities, but severe sodium-dendrite growth and side reactions prevent their practical applications, especially at high temperatures. Herein, we design an inorganic ionic conductor/gel polymer electrolyte composite, where uniformly cross-linked beta alumina nanowires are compactly coated by a poly (vinylidene fluoride-co-hexafluoropropylene)-based gel polymer electrolyte through their strong molecular interactions. These beta alumina nanowires combined with the gel polymer layer create dense and homogeneous solid-liquid hybrid sodium-ion transportation channels through and along the nanowires, which promote uniform sodium deposition and formation of a stable and flat solid electrolyte interface on the sodium metal anode. Side reactions between the sodium metal and liquid electrolyte, as well as sodium dendrite formation, are successfully suppressed, especially at $60^{\circ} \mathrm{C}$. The sodium vanadium phosphate/sodium full cells with composite electrolyte exhibit $95.3 \%$ and $78.8 \%$ capacity retention after 1000 cycles at $1 \mathrm{C}$ at $25^{\circ} \mathrm{C}$ and $60^{\circ} \mathrm{C}$, respectively.

\footnotetext{
${ }^{1}$ Shenzhen Geim Graphene Center, Tsinghua Shenzhen International Graduate School, Tsinghua University, Shenzhen 518055, China. ${ }^{2}$ State Key Laboratory of Optoelectronic Materials and Technologies, School of Materials Science and Engineering, Sun Yat-sen University, Guangzhou 510275, China. ${ }^{3}$ Hefei National Laboratory for Physical Sciences at the Microscale, Department of Materials Science and Engineering, Key Laboratory of Materials for Energy Conversion, Chinese Academy of Sciences (CAS), University of Science and Technology of China, Hefei 230026 Anhui, China. ${ }^{4}$ Chemical Sciences and Engineering Division, Argonne National Laboratory, Lemont, IL 60439, USA. ${ }^{5}$ Xiamen Institute of Rare Earth Materials, Haixi institutes, Chinese Academy of Sciences, Xiamen 361024, China. ${ }^{6}$ School of Chemical Engineering and Technology, Xi'an Jiaotong University, Xi'an 710049 , China. ${ }^{7}$ Shenzhen Environmental Science and New Energy Technology Engineering Laboratory, Tsinghua-Berkeley Shenzhen Institute (TBSI), Tsinghua University, Shenzhen 518055, China. ${ }^{8}$ Dalian National Laboratory for Clean Energy (DNL), Chinese Academy of Sciences (CAS), Dalian 116023 Liaoning, China. ${ }^{9}$ Nanoyang Group, School of Chemical Engineering and Technology, Tianjin University, Tianjin 300072, China. ${ }^{10}$ State Key Laboratory for Physical Chemistry of Solid Surface, Department of Chemistry, College of Chemistry and Chemical Engineering, Xiamen University, Xiamen 361005, China. Correspondence and requests for materials should be addressed to Y.-B.H. (email: he.yanbing@sz.tsinghua.edu.cn) or to Y.Y. (email: yanyumse@ustc.edu.cn) or to J.L. (email: junlu@anl.gov) or to F.K. (email: fykang@sz.tsinghua.edu.cn)
} 
S evere environmental issues and nonrenewable resource shortages have prompted research on high-performance rechargeable batteries for efficient storage of renewable energy from solar and wind sources ${ }^{1,2}$. Commercial lithium-ion batteries (LIBs) require expensive and rare lithium $(\mathrm{Li})$ resources, which greatly restricts the wide application of LIBs in energy storage systems. In recent years, sodium-ion batteries (SIBs) as a promising alternative to LIBs have attracted increasing attention due to the high natural abundance and low cost of Na resources ${ }^{3-6}$. A sodium $(\mathrm{Na})$ metal anode possesses a high theoretical capacity $\left(1166 \mathrm{mAh} \mathrm{g}^{-1}\right)$ and low redox potential $(-2.71 \mathrm{~V}$ vs. the standard hydrogen potential) that results in $\mathrm{Na}$ metal batteries with high working voltage and high-energy density. Therefore, there is great interest in developing $\mathrm{Na}$ metal batteries ${ }^{7-9}$, such as $\mathrm{Na}-\mathrm{O}_{2}$ batteries $^{10,11}, \mathrm{Na}$-sulfur $(\mathrm{Na}-\mathrm{S})$ batteries $^{7}$ and $\mathrm{Na}-$ metal halide batteries $^{12}$. However, utilizing $\mathrm{Na}$ metal presents huge safety issues, which are even more serious than those with $\mathrm{Li}$ metal. First, the Na metal anode suffers from nonuniform Na stripping and platting due to the inhomogenous current distribution on the surface of Na metal. It is desirable yet challenging to construct a uniform and compact solid electrolyte interphase (SEI) on $\mathrm{Na}$ metal to effectively passivate the $\mathrm{Na}$ metal surface and suppress $\mathrm{Na}$ dendrite formation. Second, similar to the Li metal, the $\mathrm{Na}$ metal is highly chemically and electrochemically reactive with organic liquid electrolytes, especially at high temperatures. The reactions lead to electrolyte decomposition, which results in the low Coulombic efficiency, poor cycling stability and severe gassing behavior of $\mathrm{Na}$ metal batteries ${ }^{13}$. These issues must be addressed to achieve $\mathrm{Na}$ metal batteries with long cycling stability and good safety for a wide range of working temperatures.

Some efforts have already been made to suppress $\mathrm{Na}$ dendrite growth, including using suitable electrolyte systems that are stable with a Na metal electrode ${ }^{14-18}$, constructing a stable artificial SEI on the Na metal surface to protect the electrode from incessant corrosion ${ }^{19-24}$, and designing $3 \mathrm{D}$ hosts with high specific surface area (e.g., porous copper matrix ${ }^{25}$, nitrogen and sulfur co-doped carbon nanotube paper ${ }^{26}$, 3D flexible carbon felt ${ }^{27}$, conductive carbonized wood ${ }^{28}$, and porous $\mathrm{Al}^{29}$ ) to manipulate Na nucleation behavior. Gel polymer electrolytes (GPEs) with a roomtemperature ionic conductivity of $10^{-3} \mathrm{~S} \mathrm{~cm}^{-1}$ have been widely applied in $\mathrm{Li}$ metal batteries to increase their safety and energy density by avoiding the leakage of electrolytes ${ }^{30-33}$, and they have also been employed in $\mathrm{Na}$ metal batteries ${ }^{14,34}$. Poly(methyl methacrylate) (PMMA) and poly(vinylidene fluoride-co-hexafluoropropylene) (PVdF-HFP)-based GPEs are the most studied types of GPEs ${ }^{35-37}$. To further improve the properties of GPEs, researchers have incorporated $\mathrm{SiO}_{2}$ additives ${ }^{38}$, commercial glass fiber (GF) membranes ${ }^{39}$, and polydopamine (PDA) ${ }^{40}$ into the above GPEs. However, these additives are nonionic conductors, which inhibit the formation of a stable $\mathrm{Na} / \mathrm{GPE}$ interface. In addition, the high-temperature stability of $\mathrm{Na}$ metal batteries has received less attention. Therefore, it is rather important to develop a homogeneous inorganic ionic conductor/GPE with high-ionic conductivity, smooth surface and compact structure to induce uniform $\mathrm{Na}$ stripping and platting and suppress dendrite formation. This composite may provide a new method to achieve stable $\mathrm{Na}$ metal batteries at wide working temperatures.

Polycrystalline beta alumina $\left(\mathrm{Al}_{2} \mathrm{O}_{3}\right)$ with high ionic conductivity and good thermal properties is a solid electrolyte material used in $\mathrm{Na}-\mathrm{S}$ and $\mathrm{Na}$-nickel chloride batteries that operate at $300-350{ }^{\circ} \mathrm{C}^{41,42}$. Beta $\mathrm{Al}_{2} \mathrm{O}_{3}$ has two similar crystalline phases of $\beta-\mathrm{Al}_{2} \mathrm{O}_{3}\left(\mathrm{NaAl}_{11} \mathrm{O}_{17}\right.$; hexagonal; $\mathrm{P} 63 / \mathrm{mmc} ; \mathrm{a}_{0}=\mathrm{b}_{0}=$ $\left.5.58 \AA, c_{0}=22.45 \AA\right)$ and $\beta^{\prime \prime}-\mathrm{Al}_{2} \mathrm{O}_{3}\left(\mathrm{NaAl}_{5} \mathrm{O}_{8}\right.$; rhombohedral; $\mathrm{R} 3 \mathrm{~m} ; \mathrm{a}_{0}=\mathrm{b}_{0}=5.60 \AA, c_{0}=33.95 \AA$ ). The $\beta^{\prime \prime}$-phase is more desirable since its ionic conductivity is $3-4$ times higher than that of the $\beta$-phase.
Here, we develop a hybrid inorganic ionic conductor/GPE composite, in which a cross-linked $\beta / \beta^{\prime \prime}-\mathrm{Al}_{2} \mathrm{O}_{3}$ Nanowires (ANs) membrane with $78.1 \% \beta^{\prime \prime}$-phase is compactly coated by PVdF-HFP-based GPE (Fig. 1a). In this innovative structure (ANs-GPE), the cross-linked ANs membrane combined with the PVdF-HFP polymer coating layer can effectively immobilize the liquid electrolyte to construct highly efficient, uniform, and continuous solid-liquid hybrid Na-ion transportation channels through and along the ANs (Fig. 1b, c). The cross-linked ANs membrane as an ionic conductor not only boosts the long-range ion motion but also creates dense and uniform Na-ion transportation channels in the ANs-GPE to induce uniform $\mathrm{Na}$ deposition and stripping, which is quite different with that using GFs-GPE (Fig. 1d, e; Supplementary Fig. 1a). As a result, a stable and flat SEI is constructed on the Na metal anode, which greatly improves the Na/ANs-GPE interface compatibility. The side reactions between $\mathrm{Na}$ metal anode and liquid electrolyte as well as $\mathrm{Na}$ dendrite formation are successfully suppressed. Full cells assembled with the $\mathrm{Na}_{3} \mathrm{~V}_{2}\left(\mathrm{PO}_{4}\right)_{3}(\mathrm{NVP})$ cathode, ANs-GPE electrolyte and $\mathrm{Na}$ metal anode present a significant improvement in cycling stability in the temperature range of $25-60^{\circ} \mathrm{C}$. Specifically, its capacity retention after 1000 cycles at $1 \mathrm{C}$ under $25^{\circ} \mathrm{C}$ and $60{ }^{\circ} \mathrm{C}$ is as high as $95.3 \%$ and $78.8 \%$, respectively. To the best of our knowledge, this work first proposes and reveals the solid-liquid hybrid $\mathrm{Na}$-ion transportation channels in hybrid electrolytes containing ceramic electrolyte and GPE. This work also highlights the importance and effectiveness of suitable composite electrolytes with inorganic ionic conductor in stabilizing solid-state $\mathrm{Na}$ metal batteries at both room and high temperatures.

\section{Results}

Characterization of ANs and ANs-PVdF-HFP composite. The ANs membrane was prepared by a simple electrospinning method and an annealing process. X-ray diffraction (XRD) patterns of the prepared membrane suggest the formation of the hybrid phase of $\beta-\mathrm{Al}_{2} \mathrm{O}_{3}$ and $\beta^{\prime \prime}-\mathrm{Al}_{2} \mathrm{O}_{3}$ after annealing at $1250^{\circ} \mathrm{C}$ (Fig. 2a). Since the $\beta-\mathrm{Al}_{2} \mathrm{O}_{3}$ and $\beta^{\prime \prime}-\mathrm{Al}_{2} \mathrm{O}_{3}$ phases have similar Xray diffraction peaks, the relative amount of the $\beta^{\prime \prime}-\mathrm{Al}_{2} \mathrm{O}_{3}$ phase can be calculated using the major peak intensities of XRD patterns of the ANs membrane, as shown in Eq. $(1)^{43}$

$$
f\left(\beta^{\prime \prime}\right)=100 \%-f(\beta)=\left(1-\frac{1.14 I(\beta)}{1.14 I(\beta)+I\left(\beta^{\prime \prime}\right)}\right) \times 100 \%
$$

where 1.14 is the I-correction factor, which is related to the relative intensities of the single-phase peaks for $\beta-\mathrm{Al}_{2} \mathrm{O}_{3}$ and $\beta^{\prime \prime}$ $-\mathrm{Al}_{2} \mathrm{O}_{3} \cdot \mathrm{I}_{\beta^{\prime \prime}}$ and $\mathrm{I}_{\beta}$ are the peak intensities at $45.9^{\circ}$ and $44.5^{\circ}$, respectively. The calculated content of $\beta^{\prime \prime}-\mathrm{Al}_{2} \mathrm{O}_{3}$ in the prepared ANs membrane is $78.1 \%$. The density functional theory (DFT) calculations show that the adsorption energies of ethylene carbonate (EC) and diethyl carbonate (DEC) on $\beta^{\prime \prime}-\mathrm{Al}_{2} \mathrm{O}_{3}(003)$ are 0.730 and $0.935 \mathrm{eV}$, respectively (Fig. $1 \mathrm{~b}, \mathrm{c}$ ), which are almost two times higher than those on $\mathrm{SiO}_{2}(001)(0.343 \mathrm{eV}$ and $0.401 \mathrm{eV}$; Supplementary Fig. 1b, c and Table 1), indicating that the crosslinked ANs membrane can immobilize the liquid electrolyte more effectively than GFs. The scanning electron microscope (SEM) image of Fig. $2 \mathrm{~b}$ presents that the ANs membrane consists of cross-linked nanowires with an average diameter of $\sim 380 \mathrm{~nm}$ (Supplementary Fig. 2), and these nanowires can be cut into small round sections, as shown in the inset of Fig. 2b. The crosssectional SEM image of the ANs membrane further confirms that the ANs are cross-linked inside the membrane (Fig. 2c), and this cross-linking benefits the transportation of $\mathrm{Na}$ ions and enhances the mechanical strength of the ANs-GPE. The transmission 
a

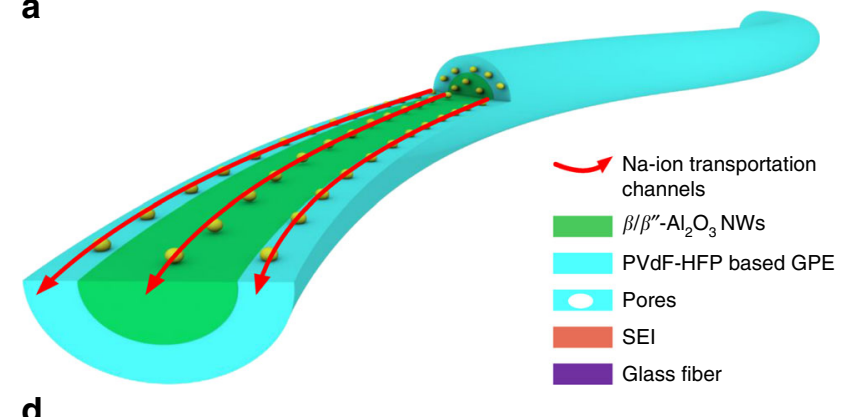

d

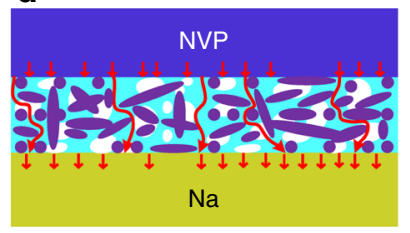

e

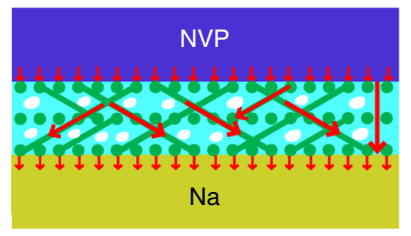

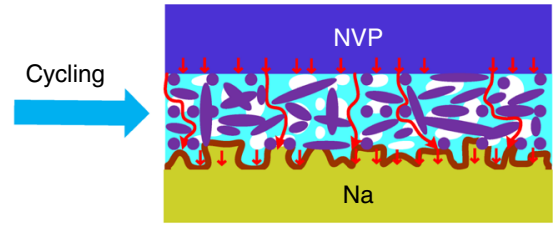

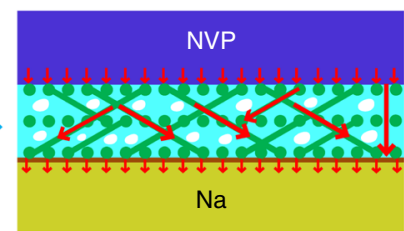

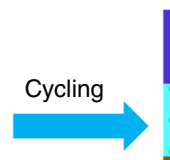

b

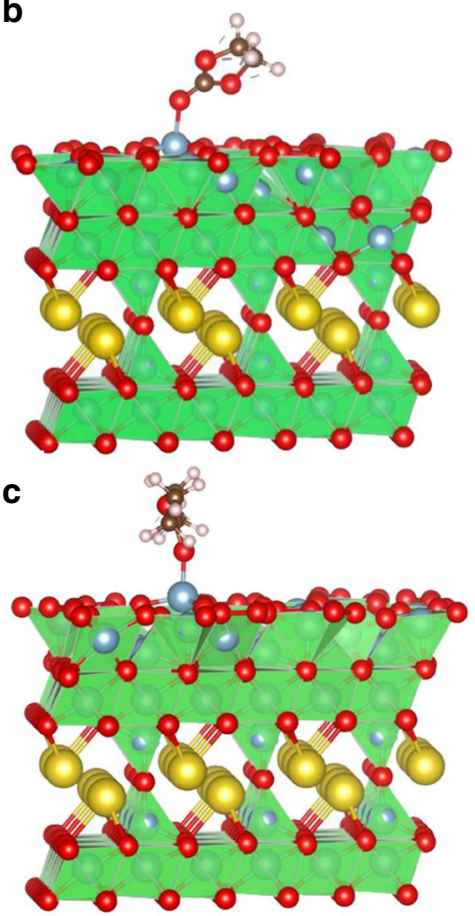

Fig. 1 Schematic of NVP/Na batteries using ANs-GPE and GFs-GPE electrolytes. a Structure and Na-ion transportation mechanism of ANs-GPE. b, c Adsorption of ethylene carbonate (EC) and diethyl carbonate (DEC) on $\beta^{\prime \prime}-\mathrm{Al}_{2} \mathrm{O}_{3}$ (003). d, e Working mechanism of NVP/Na batteries during long cycles with GFs-GPE and ANs-GPE. In the NVP/ANs-GPE/Na batteries, the flat ANs-GPE creates dense, uniform and solid-liquid hybrid Na-ion transportation channels on the surface of the Na metal anode that contribute to uniform Na deposition and the formation of stable and smooth SEl films during long cycles, while in the NVP/GFs-GPE/Na batteries, uneven Na deposition occurs due to the nonionic conductive GFs and highly porous structure of GFs-GPE

electron microscopy (TEM) image shows that the ANs consist of interconnected bamboo-like $\beta / \beta^{\prime \prime}-\mathrm{Al}_{2} \mathrm{O}_{3}$ single crystals (Fig. $2 \mathrm{~d}$ ). The corresponding selective area electron diffraction (SAED) patterns present that the two interconnected grains have the same phase, but different crystal orientations (Fig. 2e-g).

The ANs-PVdF-HFP membrane was produced by soaking the ANs membrane in PVdF-HFP solution and then naturally drying. The microstructural morphologies of the ANs-PVdF-HFP membrane are presented in Fig. $2 \mathrm{~h}-\mathrm{j}$. The surface SEM images show that the cross-linked ANs are uniformly embedded inside the dense PVdF-HFP matrix (Fig. 2h). The cross-sectional SEM image shows uniform and regular pores inside the ANs-PVdF-HFP membrane (Fig. 2i), and these pores can store the electrolyte to shorten the Na-ion migration path and enhance the ionic conductivity ${ }^{39}$. Figure $2 \mathrm{j}$ shows that the ANs are compactly coated and surrounded by PVdF-HFP layer, suggesting an excellent contact and adhesion capability between the ANs and PVdF-HFP, which is ascribed to the higher absorption ability of ANs for PVdF-HFP than GFs (Supplementary Fig. 3). The differential scanning calorimetry (DSC) curves display that the melting temperatures $\left(T_{\mathrm{m}}\right)$ decrease with the addition of ANs into the PVdF-HFP copolymers from 145.6 to $140.6^{\circ} \mathrm{C}$, indicating that the degree of crystallinity of PVdF-HFP is reduced because the introduction of ANs can enlarge the amorphous region in the polymer matrix and accelerate dynamic processes with the plasticizing effect (Supplementary Fig. 4a) ${ }^{44,45}$. In addition, the XRD patterns show that the intensity of peaks corresponding to the (020), (110), (022), (200), and (041) planes of $\gamma$-phase PVdF greatly decreases (Supplementary Fig. $4 \mathrm{~b}{ }^{44,46}$, further confirming the decrease in the crystallinity of PVdF with the addition of ANs. According to the nitrogen adsorption/desorption isotherms, the Brunauer-Emmett-Teller (BET) specific surface area of the
ANs-PVdF-HFP membrane is $2.36 \mathrm{~m}^{2} \mathrm{~g}^{-1}$, which is obviously lower than that of the ANs membrane $\left(3.73 \mathrm{~m}^{2} \mathrm{~g}^{-1}\right)$ and PVdF-HFP membrane $\left(6.45 \mathrm{~m}^{2} \mathrm{~g}^{-1}\right)$ (Supplementary Fig. 5a-c). The good compatibility between the ANs and PVdF-HFP results in a relatively dense structure of ANs-PVdF-HFP membrane. The energy dispersive spectroscopy (EDS) results for the surface and cross-sectional of ANs-PVdF-HFP membrane also prove that the ANs network is uniformly dispersed inside the ANs-PVdF-HFP membrane, and the ANs are compactly coated by the PVdF-HFP layer (Supplementary Fig. 6). Thermogravametric analysis (TGA) result presents that the ANs content is $\sim 17 \mathrm{wt} \%$ (Supplementary Fig. 7). In contrast, the GFs membrane has larger pores and looser structure compared with the cross-linked ANs, and the PVdF-HFP embedded in GFs membrane has the properties of pure porous PVdF-HFP, which results in the larger surface area of GFs-PVdF-HFP than that of GFs $\left(3.78\right.$ vs. $2.25 \mathrm{~m}^{2} \mathrm{~g}^{-1}$, Supplementary Fig. $8 \mathrm{a}-\mathrm{c}, 9 \mathrm{a}$, and $5 \mathrm{~d}, \mathrm{e})$. The thickness and mass of the ANs-PVdF-HFP membrane is $\sim 80 \mu \mathrm{m}$ and $11.5 \mathrm{mg}$ (Fig. 2i; Supplementary Table 2), which is much thinner and lighter than that of the GFs-PVdF-HFP membrane $(200 \mu \mathrm{m}$ and 31.1 mg; Supplementary Fig. 8d and Table 2). Therefore, the application of this ANs-PVdF-HFP membrane can significantly enhance the volumetric and gravimetric energy density of cells.

Electrochemical characterization of ANs-GPE-based cells. Figure 3a presents that the GFs-LE has the highest ionic conductivity of $1.45 \times 10^{-3} \mathrm{~S} \mathrm{~cm}^{-1}$ at $25^{\circ} \mathrm{C}$ due to its much larger liquid electrolyte absorption rate than ANs-GPE, GFs-GPE, and GPE (Supplementary Table 2). The ionic conductivity of ANs-GPE is $7.13 \times 10^{-4} \mathrm{~S} \mathrm{~cm}^{-1}$ at $25^{\circ} \mathrm{C}$, which is lower than that of GFs-GPE $\left(9.46 \times 10^{-4} \mathrm{~S} \mathrm{~cm}^{-1}\right)$ and close to that of 
a

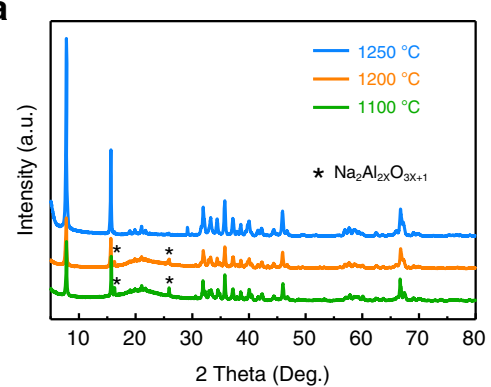

d

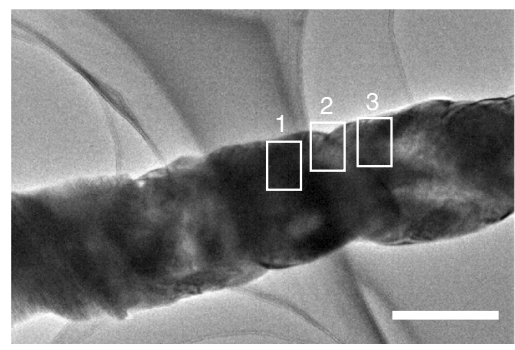

h

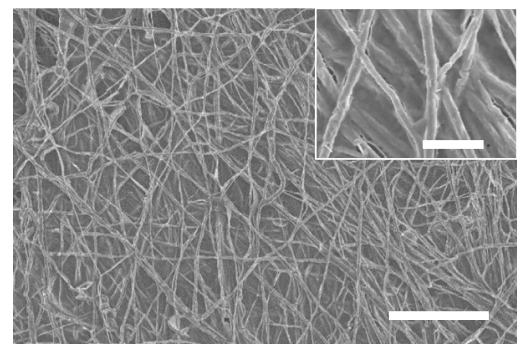

b

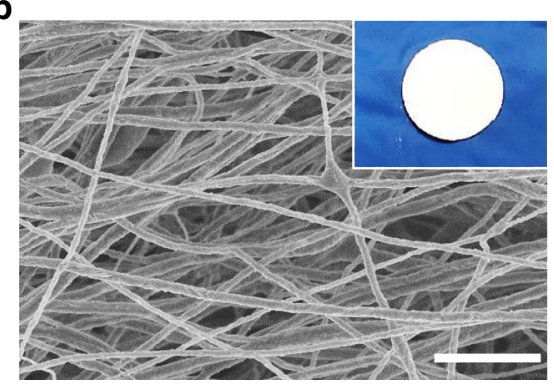

e

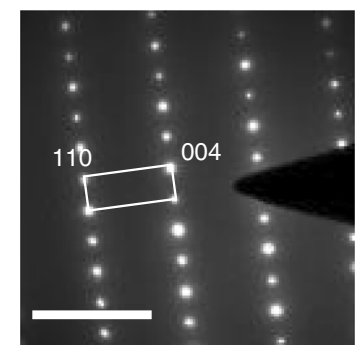

i

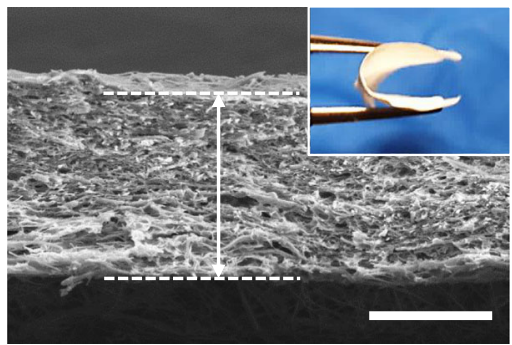

f c
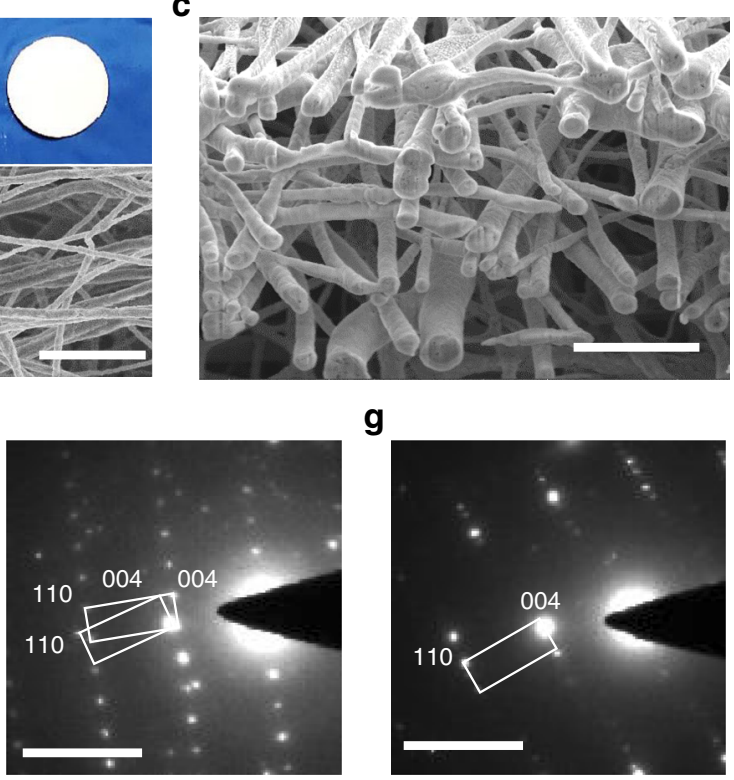

g

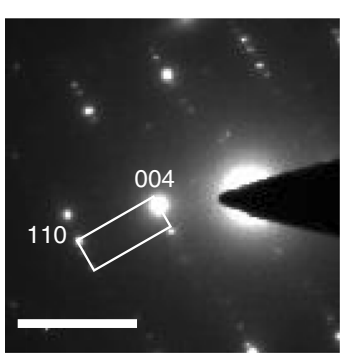

j

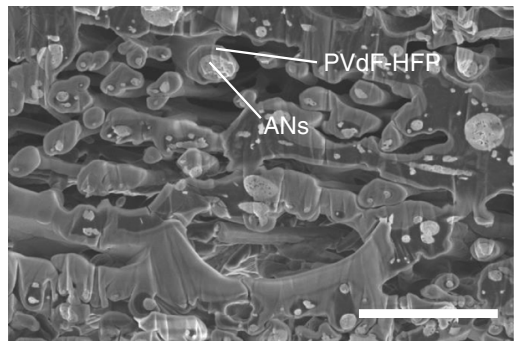

Fig. 2 Morphology and structural characterization of ANs and ANs-PVdF-HFP membranes. a XRD patterns of ANs prepared at different temperatures. b Surface and (c) cross-sectional SEM image of the ANs membrane. d TEM image of a single AN. e, $\mathbf{f}, \mathbf{g}$ SAED patterns of areas 1, 2, and 3 in (d). $\mathbf{h}$ Surface and $(\mathbf{i}, \mathbf{j})$ cross-sectional SEM images of ANs-PVdF-HFP membranes. The inset in (i) is the digital image of the ANs-PVdF-HFP membrane. Scale bars, $5 \mu \mathrm{m}$ in b, $\mathbf{c} ; 500 \mathrm{~nm}$ in $\mathbf{d} ; 51 / \mathrm{nm}$ in $\mathbf{e}, \mathbf{f}, \mathbf{g} ; 25 \mu \mathrm{m}$ in $\mathbf{h} ; 2.5 \mu \mathrm{m}$ inset in (h); $50 \mu \mathrm{m}$ in $\mathbf{i}$; and $10 \mu \mathrm{m}$ in $\mathbf{j}$

PVdF-HFP-based GPE $\left(6.79 \times 10^{-4} \mathrm{~S} \mathrm{~cm}^{-1}\right)$. Note that the liquid electrolyte absorption rate of the ANs-PVdF-HFP membrane is obviously lower than that of PVdF-HFP and GFs-PVdF-HFP membranes with an obviously more porous structure and higher surface area (Supplementary Table 2 and Supplementary Fig. 9). Therefore, the cross-linked ANs membrane combined with the PVdF-HFP polymer coating layer can effectively immobilize the liquid electrolyte that may construct highly efficient, uniform and continuous solid-liquid hybrid ionic transportation channels along the ANs. The cross-linked ANs membrane not only boosts the long-range ion motion of polymer branches in the ANs-GPE but also creates dense and uniform $\mathrm{Na}$-ion transportation channels that can improve the ionic conductivity of the whole ANs-GPE membrane. The linear sweep voltammetry (LSV) curves of both ANs-GPE and GFs-LE exhibit no oxidation peak up to $4.8 \mathrm{~V}$ vs. $\mathrm{Na} / \mathrm{Na}^{+}$, which demonstrates the high electrochemical stability of ANs-GPE (Supplementary Fig. 10).

A polarization test of the $\mathrm{Na} / \mathrm{Na}$ symmetric cells was performed to investigate the dynamic stability of the $\mathrm{Na}$ / electrolyte interface (Fig. 3b). Notably, the cells using GPE, GFs-GPE, and ANs-GPE at $0.5 \mathrm{~mA} \mathrm{~cm}^{-2}$ displays a smooth potential with a low overpotential of around $0.2 \mathrm{~V}$ from $1 \mathrm{~h}$ to $300 \mathrm{~h}$, while the $\mathrm{Na} / \mathrm{GFs}-\mathrm{LE} / \mathrm{Na}$ cell displays a short circuit after only $9 \mathrm{~h}$ due to the growth of $\mathrm{Na}$ dendrites, indicating that the application of GPE can effectively suppress $\mathrm{Na}$ dendrite growth. Therefore, the $\mathrm{Na} / \mathrm{ANs}-\mathrm{GPE} / \mathrm{Na}$ and $\mathrm{Na} / \mathrm{GFs}-\mathrm{GPE} / \mathrm{Na}$ cells present more stable polarization potential than $\mathrm{Na} / \mathrm{GPE} / \mathrm{Na}$ cell at $0.5 \mathrm{~mA} \mathrm{~cm}^{-2}$, suggesting the ANs and GFs can decrease the polarization of $\mathrm{Na}$ stripping and platting. The enlarged voltage profiles at $100 \mathrm{~h}$ and $200 \mathrm{~h}$ in the inset of Fig. $3 \mathrm{~b}$ present that the $\mathrm{Na} / \mathrm{GPE} / \mathrm{Na}$ symmetric cell shows the largest overpotential and the $\mathrm{Na} / \mathrm{GFs}-\mathrm{GPE} / \mathrm{Na}$ cell displays less overpotential than $\mathrm{Na}$ / ANs-GPE/Na cell due to the higher ionic conductivity of GFs-GPE. The polarization behavior of $\mathrm{Na} / \mathrm{Na}$ symmetrical cells using GFs-LE, GPE, GFs-GPE, and ANs-GPE was also examined at a higher current density of $1 \mathrm{~mA} \mathrm{~cm}^{-2}$ (Supplementary Fig. 11a). The $\mathrm{Na} / \mathrm{Na}$ cells using GFs-LE, GPE, and GFs-GPE exhibit short circuit after 2,75 , and $155 \mathrm{~h}$, respectively, while that using ANs-GPE presents stable polarization potential after $300 \mathrm{~h}$. Furthermore, even at higher current of $2 \mathrm{~mA} \mathrm{~cm}^{-2}$, the $\mathrm{Na}$ / ANs-GPE/Na cell can stably cycle for over $100 \mathrm{~h}$, while the $\mathrm{Na} /$ GFs-GPE/Na cell displays short circuit only after $43 \mathrm{~h}$ (Supplementary Fig. 11b). This result exhibits that the ANs induce the uniform deposition of $\mathrm{Na}$ metal for an excellent cycling stability of $\mathrm{Na} / \mathrm{Na}$ symmetrical cells.

Figure $3 \mathrm{c}$ presents the long-term cycling performances of NVP/ $\mathrm{Na}$ cells using GFs-LE, GPE, GFs-GPE, and ANs-GPE at $25^{\circ} \mathrm{C}$. The discharge capacity of the NVP/GFs-LE/Na cell slightly decreases during the initial 200 cycles at $1 \mathrm{C}$ (the corresponding current density is $0.17 \mathrm{~mA} \mathrm{~cm}^{-2}$ ), and then sharply decreases (Fig. 3c). Its capacity retention (52.0\%) is much smaller than that of the NVP/GPE/Na cell (87.9\%) after 1000 cycles. The reason for this difference is that the application of GPE can effectively suppress the growth of $\mathrm{Na}$ dendrites and reduce the side reactions 
a

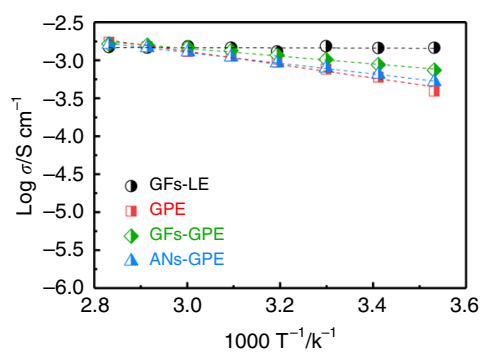

d

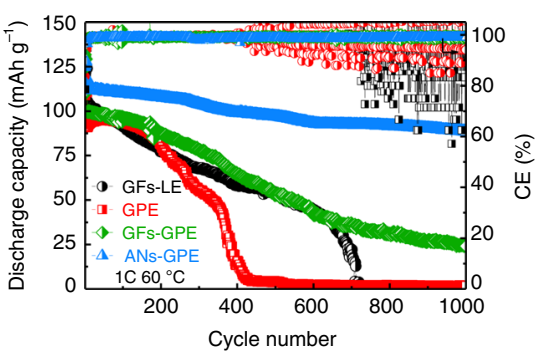

g

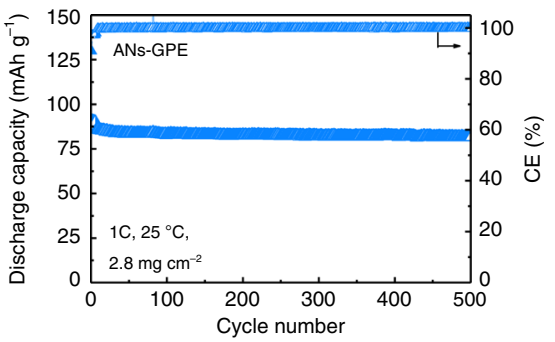

b

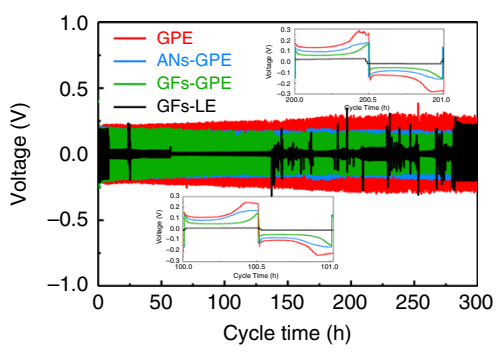

e

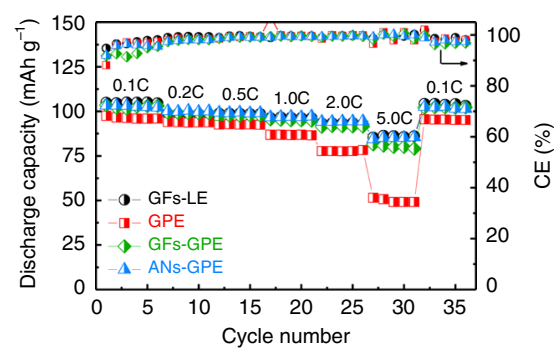

h

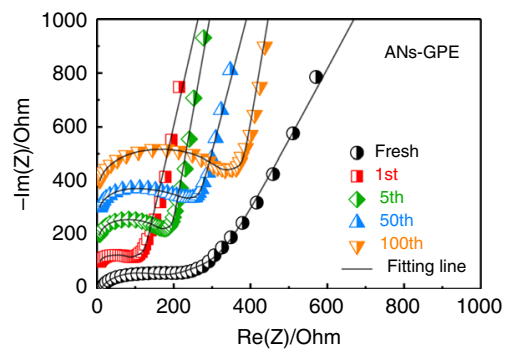

C

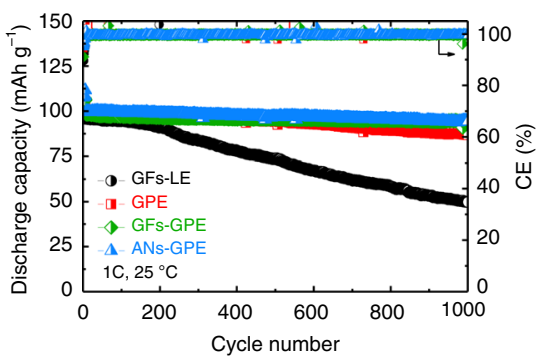

f

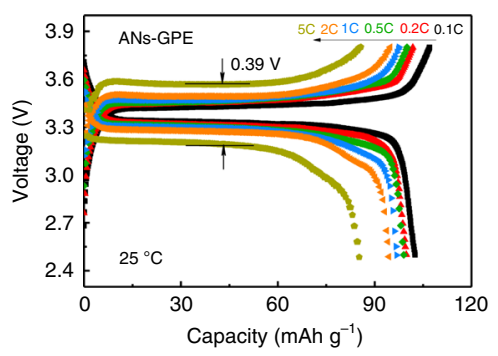

i

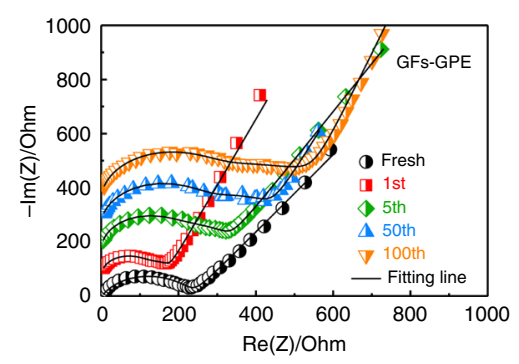

Fig. 3 Electrochemical characterizations of ANs-GPE-based cells. a lonic conductivities of GFs-LE, GPE, GFs-GPE, and ANs-GPE. b Galvanostatic cycling curves of $\mathrm{Na} / \mathrm{Na}$ symmetrical cells using GFs-LE, GPE, GFs-GPE, and ANs-GPE at a current density of $0.5 \mathrm{~mA} \mathrm{~cm}^{-2}$. c, d Long-term cycling performance of NVP/Na cells using GFs-LE, GPE, GFs-GPE, and ANs-GPE at $1 \mathrm{C}$ under $25^{\circ} \mathrm{C}$ and $60^{\circ} \mathrm{C}$. e Rate performance of NVP/Na cells using GFs-LE, GPE, GFs-GPE, and ANs-GPE. $\mathbf{f}$ Charge/discharge curves of $\mathrm{Na} / \mathrm{ANs}-\mathrm{GPE} / \mathrm{Na}$ symmetrical cells from 0.1 to $5 \mathrm{C}$. $\mathbf{g}$ Cycling performance of NVP/ANs-GPE/Na cells with NVP mass loading of $2.8 \mathrm{mg} \mathrm{cm}^{-2}$. $\mathbf{h}$, i EIS plots of NVP/ANs-GPE/Na and NVP/GFs-GPE/Na cells after different cycles

of the electrolyte with the $\mathrm{Na}$ metal anode due to the absorption ability of the GPE for the liquid electrolyte ${ }^{37}$. Furthermore, the NVP/GFs-GPE/Na and NVP/ANs-GPE/Na cells present more stable cycling performances than NVP/GPE/Na cell and exhibit almost the same capacity retention after 1000 cycles $(95.7 \%$ for NVP/GFs-GPE/Na and $95.3 \%$ for NVP/ANs-GPE/Na). The addition of GFs and ANs membranes in GPE further greatly improve the cycling performance of $\mathrm{NVP} / \mathrm{Na}$ cells at $25^{\circ} \mathrm{C}$ similar to $\mathrm{Na} / \mathrm{Na}$ symmetric cells. However, the $\mathrm{NVP} / \mathrm{Na}$ cells using GFs-LE, GPE, GFs-GPE, and ANs-GPE present quite different cycling behaviors at $60{ }^{\circ} \mathrm{C}$ (Fig. 3d). Unexpectedly, the NVP/GPE/ $\mathrm{Na}$ cell fails after only 400 cycles, and the NVP/GFs-LE/Na cell presents relatively good cycling performance but also fails after 700 cycles. The reason for failure is that the GPE becomes soft at $60{ }^{\circ} \mathrm{C}$, which compromises its ability to suppress $\mathrm{Na}$ dendrite growth during cycling, resulting in the worst cycle stability. Therefore, there are severe side reactions between the Na metal anode with dendrites and the liquid electrolyte in both the NVP/ $\mathrm{GPE} / \mathrm{Na}$ and NVP/GFs-LE/Na cells at $60^{\circ} \mathrm{C}$.

Intriguingly, the capacity retention of the NVP/ANs-GPE/Na cell after 1000 cycles is up to $78.8 \%$, which is almost three times higher than that of NVP/GFs-GPE/Na cell (24.6\%). The NVP/ ANs-GPE/Na cell presents quite stable Coulombic efficiency up to $99 \%$ during 1000 cycles, which is ascribed to that the ANs-GPE can effectively promotes the uniform $\mathrm{Na}$ deposition and the formation of a stable and flat SEI on Na metal anode. As a result, the side reaction of liquid electrolyte in ANs-GPE with $\mathrm{Na}$ metal anode can be successfully suppressed. Whereas, the Coulombic efficiency of NVP/Na cells using GFs-LE, GPE, and GFs-GPE fluctuates obviously due to the serious side reactions between $\mathrm{Na}$ metal anode and electrolyte at $60^{\circ} \mathrm{C}$, especially for that using GFs-LE and GPE. The (dis)charge overpotential of the $\mathrm{NVP} / \mathrm{ANs}-\mathrm{GPE} / \mathrm{Na}$ cell cycled for 500 times is $0.18 \mathrm{~V}$, which is much smaller than that of the NVP/GFs-GPE/Na cell $(0.63 \mathrm{~V})$ and NVP/GFs-LE/Na cell (0.64 V) (Supplementary Fig. 12a-c). Such significant improvement in the cycling performance and low polarization indicates that ANs-GPE not only remarkably suppresses the side reactions between the $\mathrm{Na}$ metal anode and electrolyte solvents even at $60{ }^{\circ} \mathrm{C}$ but also successfully suppresses $\mathrm{Na}$ dendrite growth. Although GFs-GPE can effectively suppress the side reactions of the $\mathrm{Na}$ metal anode with electrolyte at $25^{\circ} \mathrm{C}$ to achieve excellent cycling performance, these side reactions still violently occur at $60^{\circ} \mathrm{C}$ due to its highly porous structure.

The rate performance of the NVP/ANs-GPE/Na cell is comparable with that of NVP/GFs-LE/Na, but better than that of NVP/GPE/Na and NVP/GFs-GPE/Na cells (Fig. 3e). The discharge capacity of NVP using ANs-GPE at $5 \mathrm{C}$ is $85.5 \mathrm{mAh} \mathrm{g}^{-1}$, which is $83.3 \%$ of that at $0.1 \mathrm{C}$. In addition, the (dis)charge overpotential of the NVP/ANs-GPE/Na cell at $5 \mathrm{C}$ is $0.39 \mathrm{~V}$, which is obviously less than that of the NVP/GFs-GPE/Na 
cell $(0.48 \mathrm{~V}$, Fig. 3f; Supplementary Fig. 12d). The NVP/ ANs-GPE/Na cell presents an excellent rate performance and low electrochemical polarization. Notably, the specific capacity of the NVP/ANs-GPE/Na cell only slightly decreases from 99.5 to $85.8 \mathrm{mAh} \mathrm{g}^{-1}$ at $1 \mathrm{C}$ and from 94.2 to $67.0 \mathrm{mAh} \mathrm{g}^{-1}$ at $2 \mathrm{C}$ as the NVP loading increases from 1 to $2.8 \mathrm{mg} \mathrm{cm}^{-1}$, and the capacity retention is as high as $95.2 \%$ after 500 cycles at $1 \mathrm{C}$ (the current density is $0.48 \mathrm{~mA} \mathrm{~cm}^{-2}$, Fig. 3g; Supplementary Fig. 12f). The electrochemical impedance spectroscopy (EIS) results of the NVP/ANs-GPE/Na and NVP/GFs-GPE/Na cells after different numbers of cycles were obtained and simulated (Fig. 3h, i; Supplementary Fig. 13). The charge transfer resistance $\left(\mathrm{R}_{\mathrm{ct}}\right)$ of the fresh NVP/GFs-GPE/Na cell $(235.7 \mathrm{Ohm})$ is much larger than that of the fresh NVP/ANs-GPE/Na cell (149.8 Ohm). Therefore, the smooth surface of ANs-GPE improves the interfacial contact between the electrolyte and electrodes. After the first cycle, the $\mathrm{R}_{\mathrm{ct}}$ of the NVP/ANs-GPE/Na cell dramatically decreases to $30.4 \mathrm{Ohm}$, which is much less than that of the NVP/GFs-GPE/ $\mathrm{Na}$ cell $(63.3 \mathrm{Ohm})$. Furthermore, the $\mathrm{R}_{\mathrm{SEI}}$ of NVP/ANs-GPE/Na cell is only one-third that of the NVP/GFs-GPE/Na cell (39.6 $\mathrm{Ohm}$ vs. $114.0 \mathrm{Ohm})$. These results indicate that the dense and smooth surface of ANs-GPE favors uniform $\mathrm{Na}$ deposition to form a stable and flat SEI film, which greatly improves the $\mathrm{Na}$ / ANs-GPE interface compatibility with the $\mathrm{Na}$ metal anode to reduce the $R_{c t}$ and $R_{S E I}$. Therefore, the NVP/ANs-GPE/Na cell presents a better rate performance than the NVP/GFs-GPE/Na. As the cycle number increases, both the $\mathrm{R}_{\mathrm{SEI}}$ and $\mathrm{R}_{\mathrm{ct}}$ of the NVP/ ANs-GPE/Na cell slightly increase while those of the NVP/ GFs-GPE/Na cell dramatically increase, suggesting much higher interfacial and chemical stabilities between the electrolyte and $\mathrm{Na}$ metal anode using ANs-GPE than GFs-GPE.

\section{Discussion}

To identify the $\mathrm{Na}$ deposition behavior induced by different electrolytes at high temperature, $\mathrm{Cu} / \mathrm{Na}$ cells using GFs-LE, GPE, GFs-GPE, and ANs-GPE were assembled, and areal capacities of 1 and $3 \mathrm{mAh} \mathrm{cm}^{-2} \mathrm{Na}$ metal were deposited on the $\mathrm{Cu}$ surface at a current density of $0.5 \mathrm{~mA} \mathrm{~cm}^{-2}$ at $60^{\circ} \mathrm{C}$. The $\mathrm{Na}$ deposition layer using GFs -LE is extremely heterogeneous, and most of the $\mathrm{Na}$ metal was deposited inside the pores of GFs, which would greatly increase the surface area of $\mathrm{Na}$ metal and result in severe side reaction with electrolyte (Fig. $4 \mathrm{a}-\mathrm{d}$ ). As a result, the $\mathrm{Na}$ / GFs-LE/Na cell displays short circuit after only $9 \mathrm{~h}$ cycling and NVP/GFs-LE/Na cell presents very poor cycling stability at both 25 and $60{ }^{\circ} \mathrm{C}$. When the GPE is applied, the Na deposition layer has disconnected cracks and consists of nanospheres (Fig. 4e, f). Furthermore, when the deposition content increases from 1 to $3 \mathrm{mAh} \mathrm{cm}^{-2}$, some $\mathrm{Na}$ metal sheets similar to dendrites form (Fig. $4 \mathrm{~g}, \mathrm{~h}$ ). Since liquid electrolytes are mostly trapped in pores of GPE, this leads to the enrichment of $\mathrm{Na}$ ions on the $\mathrm{Cu}$ foil surface facing the pores of the GPE, but there is a lack of Na-ions on the $\mathrm{Cu}$ foil surface contacting the skeletons of the GPE ${ }^{47}$. Thus, GPE with an uneven pore size and pore distribution also cannot induce uniform $\mathrm{Na}$ deposition at $60^{\circ} \mathrm{C}$, which promotes drastic side reactions between the $\mathrm{Na}$ metal anode and electrolyte, resulting in the quite poor cycling performance of the NVP/GPE/ $\mathrm{Na}$ cell at high temperature (Fig. 3d).

Similar to using GFs-LE, the Na metal using GFs-GPE is also deposited inside the pores of GFs due to the pore structure of GFs-PVdF-HFP membranes (Fig. 4i-1), which results in the unsatisfactory cycling performance of NVP/GFs-GPE/Na cell at $60^{\circ} \mathrm{C}$. On the contrary, when the ANs-GPE was applied, the $\mathrm{Na}$ deposition layer on the surface of $\mathrm{Cu}$ foil presents a considerably uniform morphology consisting of $\mathrm{Na}$ nanospheres, which is quite different from the Na morphology obtained using GFs-LE,
GPE, and GFs-GPE (Fig. 4m, n). Interestingly, with an increase in the deposition content to $3 \mathrm{mAh} \mathrm{cm}^{-2}$, a more uniform and compact deposition layer forms (Fig. 4o, p). In addition, using similar liquid electrolyte uptake $(40 \mu \mathrm{L})$ and thickness $(80 \mu \mathrm{m})$ of GF-LE, GPE, and GFs-GPE with that of ANs-GPE, many large aggregated particles consisting of nanoparticles were also formed on the surface of $\mathrm{Cu}$ (Supplementary Figs. 14, 15). So, even with similar liquid electrolyte uptake, thickness, higherionic conductivity (Supplementary Fig. 16a) and larger surface area (Supplementary Fig. 5b-e; Fig. 16c), the GFs-LE, GPE, and GFs-GPE still cannot induce the uniform $\mathrm{Na}$ transportation to achieve flat $\mathrm{Na}$ deposition as ANs-GPE does due to their heterogeneous $\mathrm{Na}-$ ion distribution. In addition, $\mathrm{Na}$ deposition is also quite inhomogeneous on the $\mathrm{Cu}$ surface using cross-linked nonionic conductor $\gamma-\mathrm{Al}_{2} \mathrm{O}_{3}$ nanowires-GPE with similar structure to ANs-GPE even with an obvious higher ionic conductivity of $1.07 \times 10^{-3} \mathrm{~S} \mathrm{~cm}^{-1}$ at $25^{\circ} \mathrm{C}$ (Supplementary Figs. 17-19), indicating that the cross-linked $\gamma-\mathrm{Al}_{2} \mathrm{O}_{3}$ nanowires with large surface area $\left(70.18 \mathrm{~m}^{2} \mathrm{~g}^{-1}\right)$ also cannot promote the uniform $\mathrm{Na}$ metal deposition. We examined the Na-ion transference number $\left(\mathrm{t}_{\mathrm{Na}}{ }^{+}\right)$ of GFs-LE, GPE, GFs-GPE, ANs-GPE, and $\gamma-\mathrm{Al}_{2} \mathrm{O}_{3}-\mathrm{GPE}$ with same liquid electrolyte uptake $(40 \mu \mathrm{L})$ and thickness $(80 \mu \mathrm{m})$ via the method proposed by Evans et al. ${ }^{48,49}$ and their values are 0.24 , $0.21,0.29,0.37$, and 0.20, respectively (Supplementary Fig. 20). The ANs-GPE presents obvious higher $\mathrm{t}_{\mathrm{Na}}+$ than other electrolytes. The much higher $\mathrm{t}_{\mathrm{Na}}{ }^{+}$of ANs-GPE suggests that the ANs as a single-ion conductor promotes the $\mathrm{Na}$-ion transport in ANs-GPE to achieve higher and more uniform Na-ion concentrations at the interface between ANs-GPE and $\mathrm{Na}$ metal anode. Above results reinforce our conclusion that the ANs promote more uniform $\mathrm{Na}$-ion transport on the $\mathrm{Cu}$ electrode.

In order to reveal the role of networked ANs in ANs-GPE for Na-ion transportation behavior, we assembled the Li/ANs-GPE/ $\mathrm{Li}$ symmetrical cells and then charged/discharged these cells for $2 \mathrm{~h}$ and ten times at a current density of $0.5 \mathrm{~mA} \mathrm{~cm}^{-2}$ at $25^{\circ} \mathrm{C}$ and $60^{\circ} \mathrm{C}$, respectively. Then, we examined the XRD patterns, the ${ }^{7} \mathrm{Li}$ and ${ }^{23} \mathrm{Na}$ nuclear magnetic resonance (NMR) of ANs before and after cycling to analyze the substitution behavior between $\mathrm{Na}$ ion and Li ion to identify and understand the Na-ion transportation of ANs in ANs-GPE. XRD data in Fig. 5a and Supplementary Fig. $4 \mathrm{~b}$ present that a new and main phase of $\mathrm{LiAl}_{5} \mathrm{O}_{8}$ is formed in the cycled ANs-PVdF-HFP membrane, indicating that most of the $\mathrm{Na}$ ions in the ANs are substituted by the Li ions. The ${ }^{7} \mathrm{Li}$ and ${ }^{23} \mathrm{Na}$ NMR spectra of ANs and cycled ANs-PVdF-HFP membrane in $\mathrm{Li} / \mathrm{ANs}-\mathrm{GPE} / \mathrm{Li}$ cells present that the intensity of ${ }^{7} \mathrm{Li}$ signal increases apparently after cycling, while the ${ }^{23} \mathrm{Na}$ signal decreases greatly compared with that of the original ANs (Fig. 5b, c). This also indicates that the most of $\mathrm{Na}$ ions in ANs are replaced by the $\mathrm{Li}$ ions. Both of the XRD and NMR results prove that the $\mathrm{Na}$ ions in ANs are de-intercalated, and the ANs take part in ionic transportation during charge/discharge of ANs-GPE based $\mathrm{Na}$ metal batteries to form solid-liquid hybrid $\mathrm{Na}$-ion transportation channels through and along the ANs in the ANs-GPE. ANs-GPE with dense and uniform Na-ion transportation channels as well as smooth surface acts as a redistributor to regulate $\mathrm{Na}$-ion distribution which are beneficial for even $\mathrm{Na}$-ion flux to achieve homogeneous $\mathrm{Na}$ deposition ${ }^{34,47}$. Thanks to the above advantage, the $\mathrm{Na}$ dendrite growth and the side reactions between the ANs-GPE and the Na metal anode are successfully suppressed, which contributes to the excellent cycling performance of the NVP/ANs-GPE/Na cell at $60^{\circ} \mathrm{C}$. Furthermore, the $\mathrm{Cu} / \mathrm{Na}$ cells using GFs-GPE and ANs-GPE were stored for 10 days at $60^{\circ} \mathrm{C}$ to further examine the reactivity between the $\mathrm{Na}$ metal anode and the electrolyte (Fig. 4q-t). A smooth surface is maintained using ANs-GPE (Fig. 4q, r). In contrast, a very thick and lumpy layer forms when using GFs-GPE (Fig. 4s, t) due 

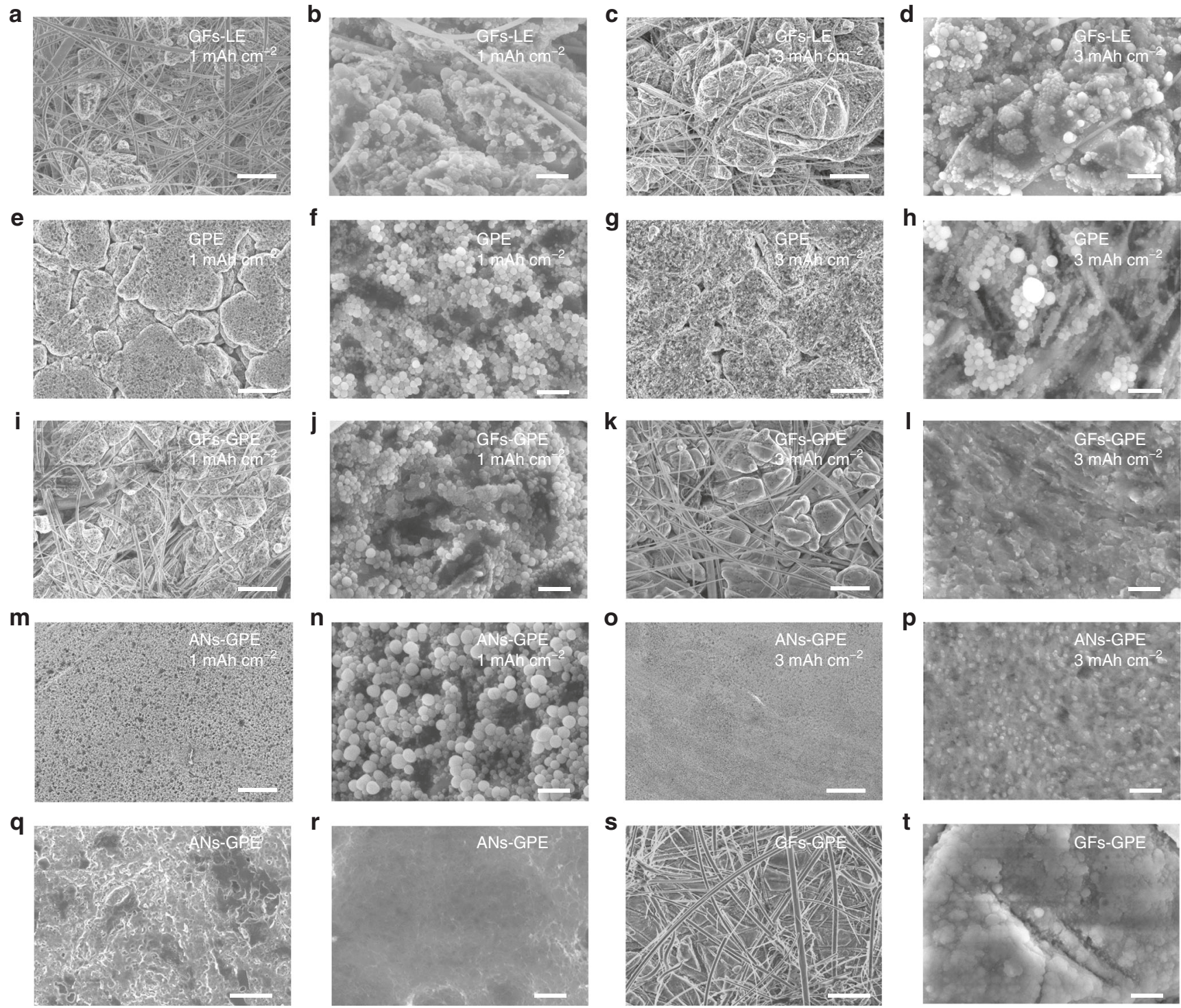

Fig. 4 SEM images of Na metal morphology. Areal capacity of 1 and $3 \mathrm{mAh} \mathrm{cm}^{-2} \mathrm{Na}$ metal was deposited on a Cu surface using GFs-LE (a, b and $\mathbf{c}, \mathbf{d}$ ), GPE $(\mathbf{e}, \mathbf{f}$ and $\mathbf{g}, \mathbf{h}), \mathrm{GFs}-\mathrm{GPE}(\mathbf{i}, \mathbf{j}$ and $\mathbf{k}, \mathbf{l})$ and ANs-GPE ( $\mathbf{m}, \mathbf{n}$ and $\mathbf{o}, \mathbf{p})$ at current densities of $0.5 \mathrm{~mA} \mathrm{~cm}{ }^{-2}$ and $60^{\circ} \mathrm{C}$. The $\mathrm{Cu} / \mathrm{Na}$ cells using $(\mathbf{q}, \mathbf{r}) \mathrm{ANs}-\mathrm{GPE}$ and $(\mathbf{s}, \mathbf{t})$ GFs-GPE were stored at $60^{\circ} \mathrm{C}$ for 10 days. The SEM images of Fig. 4b, d, f, h, j, l, n, p, r, t are magnified images of Fig. 4a, c,e, $g, i, k, m, o, q, s$. Scale bars, $10 \mu \mathrm{m}$ in $\mathbf{a}, \mathbf{c}, \mathbf{e}, \mathbf{g}, \mathbf{i}, \mathbf{k}, \mathbf{m}, \mathbf{0}, \mathbf{q}, \mathbf{s}$; and $500 \mathrm{~nm}$ in $\mathbf{b}, \mathbf{d}, \mathbf{f}, \mathbf{h}, \mathbf{j}, \mathbf{l}, \mathbf{n}, \mathbf{p}, \mathbf{r}, \mathbf{t}$

to the products from the side reactions between the $\mathrm{Na}$ anode and the electrolyte. These results indicate that the ANs-GPE could produce an ultra-uniform $\mathrm{Na}$ deposition layer on the $\mathrm{Na}$ anode and effectively prevent the continuous side reactions between the $\mathrm{Na}$ metal anode and electrolyte at high temperature.

Since the reversibility of $\mathrm{Na}$ metal anodes is largely dependent on the composition and morphology of the SEI ${ }^{50}$, SEM, EDS, and $\mathrm{X}$-ray photoelectron spectroscopy (XPS) with depth profiling were carried out to examine the SEI formed on the $\mathrm{Na}$ anodes in the NVP/ANs-GPE/Na and NVP/GFs-GPE/Na cells. The Na/ NVP cells were disassembled in the fully discharged state after 200 cycles at $60^{\circ} \mathrm{C}$. Figure 6 a shows that the surface of the $\mathrm{Na}$ anode cycled in the NVP/ANs-GPE/Na cell is quite flat and that the SEI film is considerably uniform, which is further confirmed by the homogeneous distribution of $\mathrm{F}$ element derived from the decomposition of FEC (Fig. 6b). In contrast, many Na dendrites form on the surface of the Na metal anodes cycled in the NVP/ GFs-LE/Na and NVP/GFs-GPE/Na cells, leading to the formation of a cracked SEI film (Fig. 6c; Supplementary Fig. 21a) and a heterogeneous distribution of F element (Fig. 6d; Supplementary Fig. 21b). Figure $6 \mathrm{e}-\mathrm{h}$ presents the cross-sectional SEM images and EDS maps of the NVP/ANs-GPE/Na cell after 1000 cycles, and very tight NVP/ANs-GPE and ANs-GPE/Na interfaces are observed. This result clearly confirms that the ANs-GPE has an excellent contact and affinity with both NVP cathode and $\mathrm{Na}$ metal anode, which greatly reduce their interfacial resistance. In addition, its smooth surface promotes the formation of a flat interface between ANs-GPE and $\mathrm{Na}$ metal anode. The thin and homodispersed liquid electrolyte layer at the interface decomposes to form a flat SEI film. The thickness of such a uniform SEI layer does not obviously increase with cycling due to the uniform $\mathrm{Na}$ metal deposition/stripping resulted from the highly efficient and homogeneous solid-liquid hybrid ionic transportation channels of ANs-GPE. Moreover, the ANs-GPE also helps form a thin SEI layer on the surface of the NVP side, and the morphology is very similar to that of the fresh NVP electrode, even after 1000 cycles (Supplementary Fig. 22a, b). However, GFs-LE and GFs-GPE with porous structure brings the heterogeneity of 

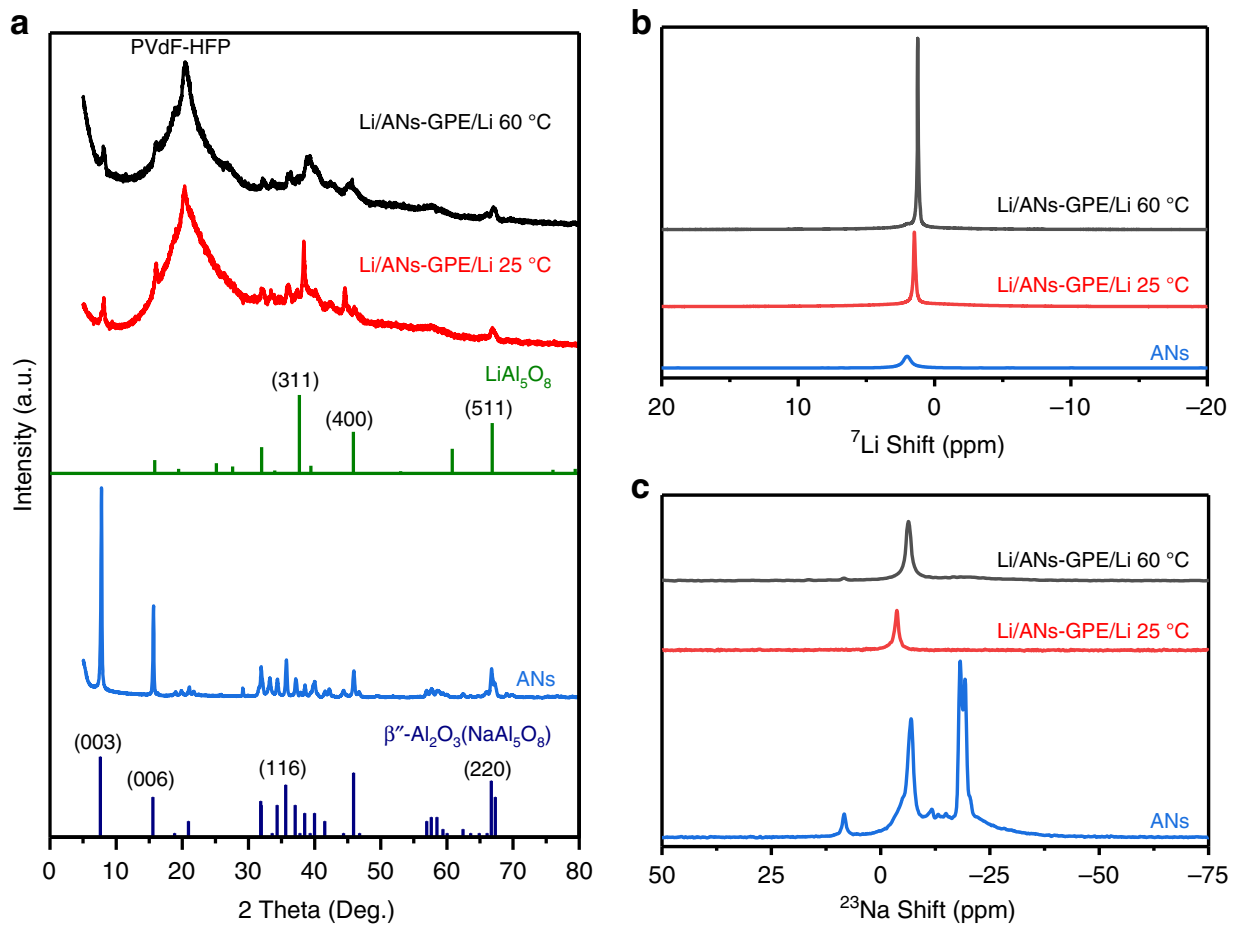

Fig. 5 Characterization of ANs before and after cycling in Li/ANs-GPE/Li cells. a XRD patterns and (b) ${ }^{7} \mathrm{Li}$ and (c) ${ }^{23} \mathrm{Na}$ NMR spectra of ANs and cycled ANs-GPE in Li/ANs-GPE/Li cells at $25^{\circ} \mathrm{C}$ and $60^{\circ} \mathrm{C}$

ion distribution and uncontrollable decomposition of electrolyte, leading to the formation of $\mathrm{Na}$ dendrites and cracked SEI film on the Na metal anode as well as thick SEI film on the NVP electrode (Supplementary Fig. 22c, d). The corresponding XRD patterns of the NVP electrodes in the discharge state with different electrolytes are similar, indicating no obvious changes in the crystallinity of NVP after 1000 cycles (Supplementary Fig. 23).

We analyzed the composition of the SEI formed on the $\mathrm{Na}$ metal anodes using ANs-GPE and GFs-GPE by XPS spectra (Fig. 6i-l; Supplementary Fig. 24). The C, O, F, Na, and Cl contents on the $\mathrm{Na}$ metal anode after sputtering for different time were calculated as shown in Fig. 6i, j. The contents of $\mathrm{C}, \mathrm{O}$, and $\mathrm{F}$ using GFs-GPE are higher than those obtained using ANs-GPE, indicating that the SEI using GFs-GPE contains more elements of $\mathrm{C}, \mathrm{O}$, and $\mathrm{F}$. In addition, the contents of $\mathrm{C}, \mathrm{O}, \mathrm{F}$, and $\mathrm{Na}$ using ANs-GPE become stable after only sputtering for $2 \mathrm{~min}$, which is much less than that using GFs-GPE (6 min). Thus, the SEI film that forms on the $\mathrm{Na}$ metal anode using ANs-GPE is considerably thinner than that formed using GFs-GPE. In the highresolution C1s XPS spectra of all the electrodes (Fig. 6k), the peaks corresponding to the species containing $\mathrm{C}-\mathrm{H}(283.3 \mathrm{eV})$, $\mathrm{C}-\mathrm{C}(284.8 \mathrm{eV}), \mathrm{C}-\mathrm{O}(286.6 \mathrm{eV}), \mathrm{C}=\mathrm{O}(288.0 \mathrm{eV}), \mathrm{ROCO}_{2} \mathrm{Na}$ $(289.1 \mathrm{eV})$, and $\mathrm{Na}_{2} \mathrm{CO}_{3}(290.0 \mathrm{eV})$ were observed, which are the main components of SEI from the decomposition products of the carbonate electrolyte $\mathrm{e}^{51-53}$. The high-resolution O1s XPS spectra confirm that the SEI contains the species of $\mathrm{Na}_{2} \mathrm{O}(529.7 \mathrm{eV})$, $\mathrm{Na}_{2} \mathrm{CO}_{3}(530.4 \mathrm{eV})$, R-COO-Na $(531.6 \mathrm{eV})$, and C-O $(533.5 \mathrm{eV})$ (Fig. 6l) ${ }^{51,54}$. The XPS peak at $535.5 \mathrm{eV}$ is assigned to Na Auger ${ }^{54}$. The XPS peak intensities of the C1s and O1s spectra of the $\mathrm{Na}$ anode using ANs-GPE are much lower than those of the anode in the GFs-GPE-based cells, especially for the peak of $\mathrm{Na}_{2} \mathrm{CO}_{3}$, suggesting that the ANs-GPE effectively mitigates the decomposition of electrolyte ${ }^{51}$. The F1s XPS spectrum presents a single peak at $683.9 \mathrm{eV}$ using ANs-GPE, which is assigned to $\mathrm{NaF}$ (Supplementary Fig. 24) 55 . In contrast, the F1s spectrum for the GFs-GPE-based cell shows two peaks at $683.7 \mathrm{eV}^{55}$ and $685.9 \mathrm{eV}^{56}$, respectively, which are assigned to $\mathrm{NaF}$ and $\mathrm{C}-\mathrm{F}$ species as the main reduction product of FEC. It is worth mentioning that the SEI composition on the cathodes is similar to that on the anodes (Supplementary Fig. 25). Therefore, the ANs-GPE effectively immobilize the liquid electrolyte and presents dense, uniform and highly efficient solid-liquid hybrid Na-ion transportation channels to induce uniform $\mathrm{Na}$ metal deposition/ stripping at the interface between the ANs-GPE and the Na metal anode, which successfully suppresses the $\mathrm{Na}$ dendrite growth and continuous side reactions of both the Na metal anode and NVP cathode with electrolyte at high temperature.

In summary, we have developed an inorganic ionic conductor/ GPE composite that combines cross-linked ANs membrane and PVdF-HFP. The uniform distribution of ANs membrane in PVdF-HFP can greatly enhance the density and uniformity of solid-liquid hybrid Na-ion transportation channel for homogenous $\mathrm{Na}$ deposition and SEI formation. The side reactions between the $\mathrm{Na}$ metal anode and the liquid electrolyte as well as $\mathrm{Na}$ dendrite formation were successfully suppressed due to the effective immobilization of electrolyte by ANs-GPE and formation of a stable and flat SEI on the Na metal anode. The NVP/ ANs-GPE/Na cell displays an excellent capacity retention $78.8 \%$ of after 1000 cycles at $1 \mathrm{C}$ and $60^{\circ} \mathrm{C}$. This work first proposes and proves the solid-liquid hybrid $\mathrm{Na}$-ion transportation channels in hybrid electrolytes containing ceramic electrolyte and GPE. This work provides a general strategy to achieve uniform $\mathrm{Na}$ metal deposition for long life $\mathrm{Na}$ metal battery technology more competitive for energy storage applications, and this strategy may be also suitable for $\mathrm{Li}$, potassium, or other metal batteries.

\section{Methods}

Materials. $\mathrm{Al}\left(\mathrm{NO}_{3}\right)_{3} \cdot 9 \mathrm{H}_{2} \mathrm{O}(99 \%)$ and $\mathrm{C}_{2} \mathrm{H}_{4} \mathrm{O}_{2}$ (99.5\%) were purchased from Macklin. $\mathrm{NaNO}_{3}$ (99\%) were obtained from Damao Chemical Reagent Factory. $\mathrm{HNO}_{3}$ (65\%-68\%) were purchased from Guangzhou Chemical Reagent Factory. Polyvinyl pyrrolidone (PVP, $\mathrm{Mw}=1,300,000)$, PVdF-HFP $(\mathrm{Mw}=400,000)$, and GFs came from Sigma Aldrich. $\mathrm{Al}\left(\mathrm{C}_{3} \mathrm{H}_{7} \mathrm{OH}\right)_{3}(99.99 \%)$ and $\mathrm{LiNO}_{3}$ (99\%) were purchased from Aladdin. Liquid electrolyte $\left(1 \mathrm{M} \mathrm{NaClO}_{4}\right.$ in ethylene carbonate (EC) and diethyl carbonate (DEC) with 5\% fluoroethylene carbonate (FEC)) was obtained from Suzhou Qianmin Chemical Reagent Company. 
a

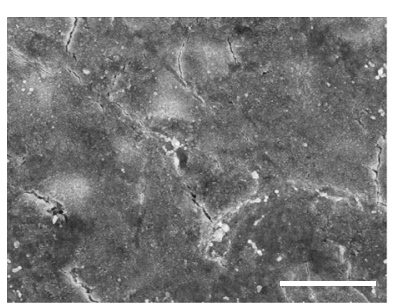

e

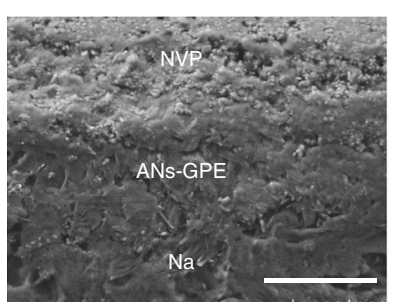

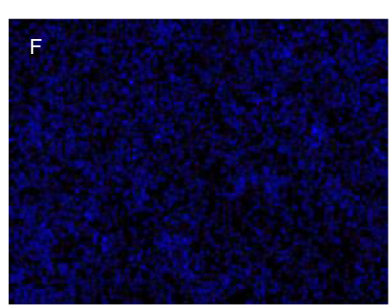

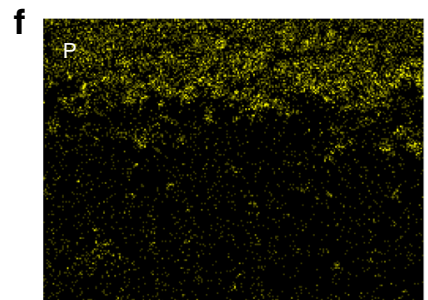

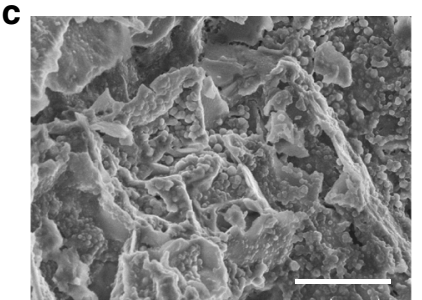

$\mathbf{g}_{\mathrm{Na}}$

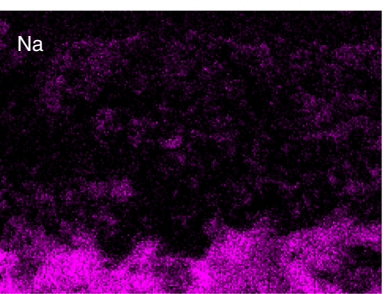

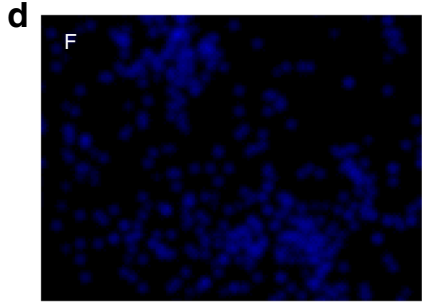

h

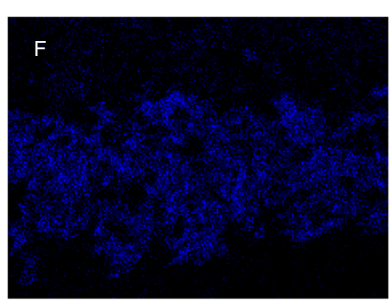

i

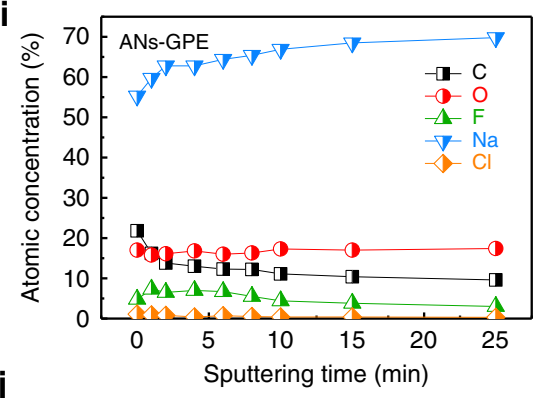

j

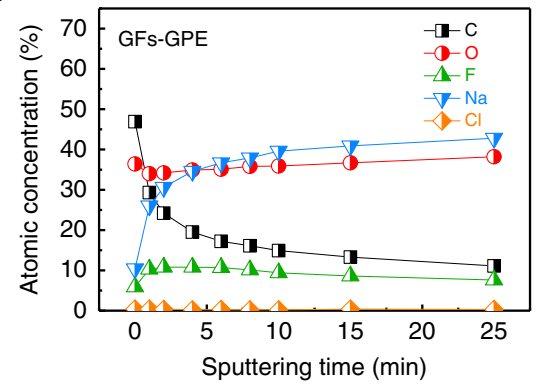

$\mathbf{k}$

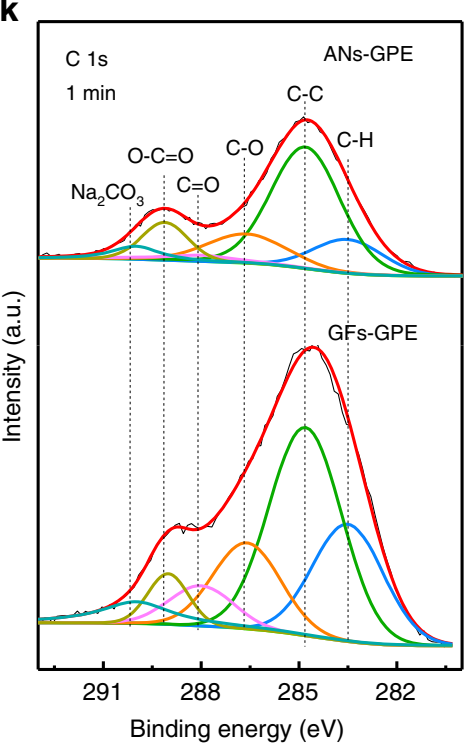

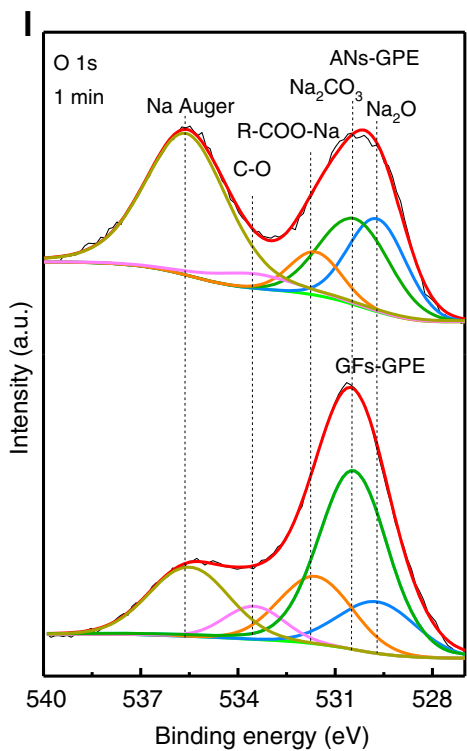

Fig. 6 Morphology and components analysis of the Na metal anode after cycling at $1 \mathrm{C}$ using ANs-GPE and GFs-GPE at $60^{\circ} \mathrm{C}$. a-d SEM and EDS images of the Na metal anode surface after 200 cycles. e-h SEM and EDS images of cross-section of the NVP/ANs-GPE/Na cell after 1000 cycles. $\mathbf{i}, \mathbf{j}$ Atomic concentration of various elements with sputtering time. $\mathbf{k}$, I High-resolution C1s and O1s XPS spectra of Na anodes after 200 cycles. Scale bars, $5 \mu \mathrm{m}$ in $\mathbf{a}$, c; and $50 \mu \mathrm{m}$ in $\mathbf{e}$

Preparation of ANs membrane. The ANs membranes were synthesized via an electrospinning method and following an annealing process. In a typical procedure, $8 \mathrm{mmol}$ of $\mathrm{Al}\left(\mathrm{NO}_{3}\right)_{3} \cdot 9 \mathrm{H}_{2} \mathrm{O}, 1.4 \mathrm{mmol}$ of $\mathrm{LiNO}_{3}$, and $9 \mathrm{mmol}$ of $\mathrm{NaNO}_{3}$ were dissolved in $9.2 \mathrm{~mL}$ of deionized (DI) water by magnetic stirring at room temperature. Then, $2.9 \mathrm{~mL}$ of $\mathrm{HNO}_{3}$ and $1.9 \mathrm{~mL}$ of $\mathrm{C}_{2} \mathrm{H}_{4} \mathrm{O}_{2}$ were added into the above solution. After that, $40 \mathrm{mmol}$ of $\mathrm{Al}\left(\mathrm{C}_{3} \mathrm{H}_{7} \mathrm{OH}\right)_{3}$ was added and stirred for $24 \mathrm{~h}$. Next, $0.36 \mathrm{~g}$ of PVP was added and stirred $12 \mathrm{~h}$ to obtain a homogeneous stable spinning sol, which was then electrospun into ANs membrane precursors under the electrospinning voltage of $18 \mathrm{kV}$ and pumping rate of $1 \mathrm{~mL} \mathrm{~h}^{-1}$. The obtained nanowires membranes were dried in a vacuum oven for $12 \mathrm{~h}$ and then heat treated in a muffle furnace at $600^{\circ} \mathrm{C}$ for $1 \mathrm{~h}$ with the heating rate of $1^{\circ} \mathrm{C} \mathrm{min}-1$. At last, the membrane was further heated up to respective 1100,1200 , and $1250^{\circ} \mathrm{C}$ for $1 \mathrm{~h}$ with the heating rate of $5^{\circ} \mathrm{C} \mathrm{min}^{-1}$ to obtain the $\beta / \beta^{\prime \prime}-\mathrm{Al}_{2} \mathrm{O}_{3}$ nanowires (ANs) membrane. The $\gamma-\mathrm{Al}_{2} \mathrm{O}_{3}$ membranes were prepared using the similar method and the details are shown in Supplementary Methods.

Preparation of ANs-GPE. PVdF-HFP solutions were prepared by dissolving $0.75 \mathrm{~g}$ of PVdF-HFP in a solution with $13.5 \mathrm{~g}$ of acetone and $0.75 \mathrm{~g}$ of ethanol by magnetic stirring at $50^{\circ} \mathrm{C}$ for $2 \mathrm{~h}$. The transparent solution was coated onto the ANs membrane by a dip-coating process at $25^{\circ} \mathrm{C}$ and then naturally dried. As a comparison, the GFs-PVdF-HFP and $\gamma-\mathrm{Al}_{2} \mathrm{O}_{3}-\mathrm{PVdF}-\mathrm{HFP}$ composite membranes were prepared by coating the PVdF-HFP solutions onto the GFs membrane and $\gamma-\mathrm{Al}_{2} \mathrm{O}_{3}$ nanowire membrane using the same method. The pure PVdF-HFP membrane was prepared by adding the PVdF-HFP solutions into a glass dish and then naturally dried. The membranes were immersed in liquid electrolyte $(1 \mathrm{M}$ $\mathrm{NaClO}_{4}$ in ethylene carbonate (EC) and diethyl carbonate(DEC) with 5\% fluoroethylene carbonate (FEC)) for $12 \mathrm{~h}$ in an argon-filled glove box (M. Braun) to obtain the ANs-GPE, GFs-GPE, $\gamma-\mathrm{Al}_{2} \mathrm{O}_{3}-\mathrm{GPE}$, and GPE for the battery assemblies and other characterizations.

Fabrication of cells. The NVP cathode material was synthesized by a simple method according to a previous work ${ }^{57}$. The phase and morphology of NVP were characterized by XRD, Raman, SEM, and TEM analyses (Supplementary Fig. 26). Pure carbon-coated NVP with a flower-like morphology was synthesized. The cathode was prepared by mixing NVP particles, super P, and PVdF in a weight ratio of 7:2:1 by NMP, then casting the slurry on Al foil. After drying at $80^{\circ} \mathrm{C}$, the cathodes with NVP loading of $\sim 1$ and $2.8 \mathrm{mg} \mathrm{cm}^{-2}$ particles were obtained. CR2032 coin cells were assembled using $\mathrm{Na}$ foil as a anode, NVP as a cathode, and ANs-GPE, GFs-GPE, GPE, or GFs-LE as an electrolyte in a glove box.

Materials characterization. The X-ray diffraction (XRD) measurement of the samples was characterized on a Bruker D8 Advance with $\mathrm{Cu}-\mathrm{Ka}$ radiation. Their morphologies and structures were analyzed by a scanning electron microscope (SEM, HITACH S4800) with energy-dispersive spectroscopy (EDS) for elemental analysis and a field emission transmission electron microscope (FE-TEM, FEI Tecnai F30). X-ray photoelectron spectroscopy (XPS) measurement was collected on a PHI 5000 VersaProbe II instrument, and depth profiling was obtained using 
Ar gas cluster ion beam (Ar-GCIB) sputtering at $15 \mathrm{kV}$ and $35 \mathrm{nA}$ over a $2 \times 2 \mathrm{~mm}$ area. The solid-state ${ }^{7} \mathrm{Li}$ and ${ }^{23} \mathrm{Na}$ nuclear magnetic resonance (NMR) were performed in a $9.4 \mathrm{~T}$ magnetic field with a Bruker $400 \mathrm{MHz}$ AVANCE III spectrometer. The ANs and cycled ANs-PVdF-HFP membrane are filled into $4 \mathrm{~mm}$ rotors. The solid-state ${ }^{7} \mathrm{Li}$ and ${ }^{23} \mathrm{Na}$ magic angle spinning (MAS) NMR spectra are acquired using single pulse under the spinning frequency of $12 \mathrm{kHz}$. The specific surface areas were characterized on a micromeritics ASAP 2020 apparatus with the BET method. Raman spectra were recorded by a LabRAM HR800 spectrometer using 532 incident radiation. Thermogravametric analysis (TGA) was performed using a Netzsch STA $449 \mathrm{~F} 3$ thermal analyzer from room temperature to $800^{\circ} \mathrm{C}$ at a heating rate of $10^{\circ} \mathrm{C} \mathrm{min}^{-1}$ in air atmosphere. The differential scanning calorimetry (DSC) measurements were performed on the above thermal analyzer at a rate of $10^{\circ} \mathrm{C} \mathrm{min}-1$ in the $30-300{ }^{\circ} \mathrm{C}$ temperature range under $\mathrm{N}_{2}$ atmosphere. The amount of liquid electrolyte uptake $(\eta)$ was measured by soaking slices in liquid electrolyte for $12 \mathrm{~h}$, and recording the weight after wiping excess liquid electrolyte off with filter papers. Then, $\eta$ was calculated using the following equation:

$$
\eta=\frac{W_{t}-W_{0}}{W_{0}} \times 100 \%
$$

Where $W_{0}$ is the weight of the dry membrane and $W_{\mathrm{t}}$ is the weight of the membrane after soaking in liquid electrolyte.

Electrochemical measurements. The ionic conductivity of ANs-GPE, GFs-GPE, $\gamma-\mathrm{Al}_{2} \mathrm{O}_{3}-\mathrm{GPE}$, GPE, and GFs-LE was measured by EIS from $10^{6}$ to $10^{2} \mathrm{~Hz}$ with a $5 \mathrm{mV}$ AC oscillation on a VMP3 multichannel electrochemical station (Bio Logic Science Instruments, France). The test cells were assembled by a small piece of ANs-GPE, GFs-GPE, $\gamma-\mathrm{Al}_{2} \mathrm{O}_{3}-\mathrm{GPE}$, GPE, or GFs-LE slice sandwiched between two stainless-steel blocking electrodes. Prior to the EIS measurements, the cells were kept at each test temperature (from 10 to $80^{\circ} \mathrm{C}$ ) for $1 \mathrm{~h}$ to reach the thermal equilibrium. The LSV curves were examined from the open-circuit voltage to $5.5 \mathrm{~V}$ versus $\mathrm{Na} / \mathrm{Na}^{+}$at a scanning rate of $1 \mathrm{mV} \mathrm{s}{ }^{-1}$ using a VMP3 multichannel electrochemical station. Galvanostatic charge/discharge tests of cells were performed on a battery test system (LAND CT2001A) with a voltage range from 2.5 to $3.8 \mathrm{~V}$ at $25^{\circ} \mathrm{C}$ and $60^{\circ} \mathrm{C}$. The EIS of cells cycled for different times was examined using the VMP3 multichannel electrochemical station in the frequency range of $10^{-2}-10^{5} \mathrm{~Hz}$ by applying a $5 \mathrm{mV}$ AC oscillation. The cycled cells were transferred into a glove box and dissembled for further examination. The Na metal anodes were repeatedly rinsed with DMC and vacuum dried for $12 \mathrm{~h}$ to remove residual solvent. The Na metal anodes were transferred into a chamber with a sealed Ar-filled vessel for SEM and XPS examination. $\mathrm{Na} / \mathrm{Na}$ symmetric cells were assembled and charged/discharged for $0.5 \mathrm{~h}$ at a current densities of $0.5,1$, and 2 $\mathrm{mA} \mathrm{cm}{ }^{-2}$. The Li/ANs-GPE/Li symmetrical cells were assembled and then charged/discharged these cells for $2 \mathrm{~h}$ and ten times with a current density of $0.5 \mathrm{~mA} \mathrm{~cm}-2$ at $25^{\circ} \mathrm{C}$ and $60^{\circ} \mathrm{C}$, respectively. The test method of the Na-ion transference number $\left(\mathrm{t}_{\mathrm{Na}}{ }^{+}\right)$of ANs-GPE, GFs-GPE, $\gamma-\mathrm{Al}_{2} \mathrm{O}_{3}-\mathrm{GPE}$, GPE, and GFs-LE is shown in Supplementary Methods.

Computational details. The calculations were performed by using the projectoraugmented wave method (PAW) within the framework of density functional theory (DFT) as implemented in the Vienna ab initio Simulation Package (VASP). The interaction between electrons was treated by the exchange-correlation functional of the generalized gradient approximation (GGA) with Perdew-Burke-Ernzerh (PBE) parametrization. We used potentials with electronic configurations of $S i\left(3 \mathrm{~s}^{2} 3 \mathrm{p}^{2}\right)$, $\mathrm{Al}\left(3 \mathrm{~s}^{2} 3 \mathrm{p}^{1}\right), \mathrm{Na}(3 \mathrm{~s}), \mathrm{O}\left(2 \mathrm{~s}^{2} 2 \mathrm{p}^{4}\right), \mathrm{C}\left(2 \mathrm{~s}^{2} 2 \mathrm{p}^{2}\right)$, and $\mathrm{H}(1 \mathrm{~s})$. The cutoff energy of the plane wave basis was set to $450 \mathrm{eV}$. Both the slabs of $\mathrm{Si}(001)$ and $\mathrm{NaAl}_{5} \mathrm{O}_{8}(003)$ were modeled in a $p(3 \times 3)$, in which the terminal exposed surface was constructed with $\mathrm{O}$ atoms. A Monkhorst-Pack scheme of $5 \times 5 \times 1 \mathrm{k}$-meshes was employed for both slabs, of which a vacuum of $20 \AA$ was applied to prevent spurious interaction with periodic images. Calculations stopped when the accuracies reached the required convergence criteria of $1 \times 10^{-2} \mathrm{eV} \AA^{-1}$ for the residual forces on ions and $1 \times 10^{-4} \mathrm{eV}$ for the total energy difference in the electronic self-consistent loop.

The binding strength of EC (DEC and PVdF-HFP monomer) on the surface of the $\mathrm{SiO}_{2}(001)$ (or $\mathrm{NaAl}_{5} \mathrm{O}_{8}(003)\left(\beta^{\prime \prime}-\mathrm{Al}_{2} \mathrm{O}_{3}\right)$ ) slab can be calculated by the following equation:

$$
E_{\mathrm{be}}=E_{\mathrm{s}, \mathrm{a}}-E_{\mathrm{s}}-E_{\mathrm{a}}
$$

where $E_{\mathrm{be}}$ is the binding energy of $\mathrm{EC}$ on the $\mathrm{SiO}_{2}(001), E_{\mathrm{s}, \mathrm{a}}$ is the total energy of the $\mathrm{SiO}_{2}(001)$ slab with adsorbed EC, $E_{\mathrm{s}}$ is the total energy of a clean $\mathrm{SiO}_{2}(001)$ slab without EC, and $E_{\mathrm{a}}$ is the energy of EC.

\section{Data availability}

The authors declare that all the relevant data are available within the paper and its Supplementary Information file or from the corresponding author upon reasonable request.

Received: 21 January 2019 Accepted: 8 August 2019

Published online: 18 September 2019

\section{References}

1. Tarascon, J. M. \& Armand, M. Issues and challenges facing rechargeable lithium batteries. Nature 414, 359-367 (2001).

2. Nitta, N., Wu, F. X., Lee, J. T. \& Yushin, G. Li-ion battery materials: present and future. Mater. Today 18, 252-264 (2015).

3. Pan, H. L., Hu, Y.-S. \& Chen, L. Q. Room-temperature stationary sodium-ion batteries for large-scale electric energy storage. Energy Environ. Sci. 6, 2338-2360 (2013)

4. Xin, S., Yin, Y.-X., Guo, Y.-G. \& Wan, L.-J. A high-energy room-temperature sodium-sulfur battery. Adv. Mater. 26, 1261-1265 (2014).

5. Li, W. H. et al. Confined amorphous red phosphorus in MOF-derived Ndoped microporous carbon as a superior anode for sodium-ion battery. $A d v$ Mater. 29, 1605820 (2017).

6. Hwang, J.-Y., Myung, S.-T. \& Sun, Y.-K. Sodium-ion batteries: present and future. Chem. Soc. Rev. 46, 3529-3614 (2017).

7. Wei, S. Y. et al. A stable room-temperature sodium-sulfur battery. Nat. Commun. 7, 11722 (2016)

8. Yu, X. W. \& Manthiram, A. Ambient-temperature sodium-sulfur batteries with a sodiated nafion membrane and a carbon nanofiber-activated carbon composite electrode. Adv. Energy Mater. 5, 1500350 (2015).

9. Kim, B.-R. et al. High performance $\mathrm{Na}-\mathrm{CuCl}_{2}$ rechargeable battery toward room temperature ZEBRA-type battery. Adv. Energy Mater. 6, 1600862 (2016).

10. Kim, J. et al. Dissolution and ionization of sodium superoxide in sodiumoxygen batteries. Nat. Commun. 7, 10670 (2016).

11. Hartmann, P. et al. A rechargeable room-temperature sodium superoxide $\left(\mathrm{NaO}_{2}\right)$ battery. Nat. Mater. 12, 228-232 (2013).

12. Li, G. S. et al. Advanced intermediate temperature sodium-nickel chloride batteries with ultra-high energy density. Nat. Commun. 7, 10683 (2016).

13. Chen, X. et al. Ion-solvent complexes promote gas evolution from electrolytes on a sodium metal anode. Angew. Chem. Int. Ed. 57, 734-737 (2018).

14. Che, H. Y. et al. Electrolyte design strategies and research progress for roomtemperature sodium-ion batteries. Energy Environ. Sci. 10, 1075-1101 (2017).

15. Zheng, J. M. et al. Extremely stable sodium metal batteries enabled by localized high-concentration electrolytes. ACS Energy Lett. 3, 315-321 (2018).

16. Basile, A. et al. Ionic liquids and organic ionic plastic crystals advanced electrolytes for safer high performance sodium energy storage technologies. Adv. Energy Mater. 8, 1703491 (2018).

17. Wang, H., Wang, C. L., Matios, E. \& Li, W. Y. Facile stabilization of the sodium metal anode with additives: unexpected key role of sodium polysulfide and adverse effect of sodium nitrate. Angew. Chem. Int. Ed. 57, 7734-7737 (2018).

18. Shi, Q. W., Zhong, Y. R., Wu, M., Wang, H. Z. \& Wang, H. L. Highperformance sodium metal anodes enabled by a bifunctional potassium salt. Angew. Chem. Int. Ed. 57, 9069-9072 (2018).

19. Wei, S. Y. et al. Highly stable sodium batteries enabled by functional ionic polymer membranes. Adv. Mater. 29, 1605512 (2017).

20. Luo, W. et al. Ultrathin surface coating enables the stable sodium metal anode. Adv. Energy Mater. 7, 1601526 (2017).

21. Zhao, Y. et al. Superior stable and long life sodium metal anodes achieved by atomic layer deposition. Adv. Mater. 29, 1606663 (2017).

22. Zhao, Y. et al. Inorganic-organic coating via molecular layer deposition enables long life sodium metal anode. Nano Lett. 17, 5653-5659 (2017)

23. Zhao, Q. et al. Building organic/inorganic hybrid interphases for fast interfacial transport in rechargeable metal batteries. Angew. Chem. Int. Ed. 57, 992-996 (2018).

24. Tu, Z. Y. et al. Fast ion transport at solid-solid interfaces in hybrid battery anodes. Nat. Energy 3, 310-316 (2018).

25. Wang, C. L., Wang, H., Matios, E., Hu, X. F. \& Li, W. Y. A chemically engineered porous copper matrix with cylindrical core-shell skeleton as a stable host for metallic sodium anodes. Adv. Funct. Mater. 28, 1802282 (2018).

26. Sun, B. et al. Dendrite-free sodium-metal anodes for high-energy sodiummetal batteries. Adv. Mater. 30, e1801334 (2018).

27. Chi, S.-S., Qi, X.-G., Hu, Y.-S. \& Fan, L.-Z. 3D flexible carbon felt host for highly stable sodium metal anodes. Adv. Energy Mater. 8, 1702764 (2018).

28. Luo, W. et al. Encapsulation of metallic $\mathrm{Na}$ in an electrically conductive host with porous channels as a highly stable Na metal anode. Nano Lett. 17, 3792-3797 (2017).

29. Liu, S. et al. Porous $\mathrm{Al}$ current collector for dendrite-free $\mathrm{Na}$ metal anodes. Nano Lett. 17, 5862-5868 (2017).

30. Manthiram, A., Yu, X. W. \& Wang, S. F. Lithium battery chemistries enabled by solid-state electrolytes. Nat. Rev. Mater. 2, 16103 (2017).

31. Liu, W. et al. Enhancing ionic conductivity in composite polymer electrolytes with well-aligned ceramic nanowires. Nat. Energy 2, 17035 (2017).

32. Fu, K. et al. Three-dimensional bilayer garnet solid electrolyte based high energy density lithium metal-sulfur batteries. Energy Environ. Sci. 10, 1568-1575 (2017). 
33. Gao, Z. H. et al. All-solid-state batteries: promises, challenges, and recent progress of inorganic solid-state electrolytes for all-solid-state lithium batteries. Adv. Mater. 30, 1870122 (2018).

34. Ma, J.-L. et al. Suppressing sodium dendrites by multifunctional polyvinylidene fluoride (PVDF) interlayers with nonthrough pores and high flux/affinity of sodium ions toward long cycle life sodium oxygen-batteries. Adv. Funct. Mater. 28, 1703931 (2018).

35. Xue, Y. \& Quesnel, D. J. Synthesis and electrochemical study of sodium ion transport polymer gel electrolytes. RSC Adv. 6, 7504-7510 (2016).

36. Gao, H. C., Zhou, W. D., Park, K. \& Goodenough, J. B. A sodium-ion battery with a low-cost cross-linked gel-polymer electrolyte. Adv. Energy Mater. 6, 1600467 (2016).

37. Yang, Y. Q., Chang, Z., Li, M. X., Wang, X. W. \& Wu, Y. P. A sodium ion conducting gel polymer electrolyte. Solid State Ion. 269, 1-7 (2015).

38. Kumar, D. \& Hashmi, S. A. Ion transport and ion-filler-polymer interaction in poly(methyl methacrylate)-based, sodium ion conducting, gel polymer electrolytes dispersed with silica nanoparticles. J. Power Sources 195, 5101-5108 (2010).

39. Kim, J. I., Choi, Y., Chung, K. Y. \& Park, J. H. A structurable gel-polymer electrolyte for sodium ion batteries. Adv. Funct. Mater. 27, 1701768 (2017)

40. Gao, H. C., Guo, B. K., Song, J., Park, K. \& Goodenough, J. B. A composite gelpolymer/glass-fiber electrolyte for sodium-ion batteries. Adv. Energy Mater. 5, 1402235 (2015).

41. Hueso, K. B., Palomares, V., Armand, M. \& Rojo, T. Challenges and perspectives on high and intermediate-temperature sodium batteries. Nano Res. 10, 4082-4114 (2017)

42. Lu, Y., Li, L., Zhang, Q., Niu, Z. Q. \& Chen, J. Electrolyte and interface engineering for solid-state sodium batteries. Joule 2, 1747-1770 (2018).

43. Pekarsky, A. \& Nicholson, P. S. The relative stability of spray-frozen/freezedried $\beta^{\prime \prime}-\mathrm{Al}_{2} \mathrm{O}_{3}$ powders. Mater. Res. Bull. 15, 1517-1524 (1980).

44. Kim, K. M., Park, N.-G., Ryu, K. S. \& Chang, S. H. Characterization of poly (vinylidenefluoride-co-hexafluoropropylene)-based polymer electrolyte filled with $\mathrm{TiO}_{2}$ nanoparticles. Polymer 43, 3951-3957 (2002).

45. Liang, Y. F. et al. A superior composite gel polymer electrolyte of $\mathrm{Li}_{7} \mathrm{La}_{3} \mathrm{Zr}_{2} \mathrm{O}_{12}$-poly(vinylidene fluoride-hexafluoropropylene) (PVDF-HFP) for rechargeable solid-state lithium ion batteries. Mater. Res. Bull. 102, 412-417 (2018).

46. Marand, H. L., Stein, R. S. \& Stack, G. M. Isothermal crystallization of poly (vinylidene fluoride) in the presence of high static electric fields. I. Primary nucleation phenomenon. J. Polym. Sci. Pol. Phys. 26, 1361-1383 (1988).

47. Zhao, C.-Z. et al. An ion redistributor for dendrite-free lithium metal anodes. Sci. Adv. 4, eaat3446 (2018).

48. Evans, J., Vincent, C. A. \& Bruce, P. G. Electrochemical measurement of transference numbers in polymer electrolytes. Polymer 28, 2324-2328 (1987).

49. Kumar, D. \& Hashmi, S. A. Ion transport and ion-filler-polymer interaction in poly(methylmethacrylate)-based, sodium ion conducting, gel polymer electrolytes dispersed with silica nanoparticles. J. Power Sources 195, 5101-5108 (2010).

50. Xu, K. Electrolytes and interphases in Li-ion batteries and beyond. Chem. Rev. 114, 11503-11618 (2014)

51. Kim, Y.-J. et al. Enhancing the cycling stability of sodium metal electrodes by building an inorganic-organic composite protective layer. ACS Appl. Mater. Inter. 9, 6000-6006 (2017).

52. Lv, M., Zheng, F., Wang, Q. H., Wang, T. M. \& Liang, Y. M. Surface structural changes, surface energy and antiwear properties of polytetrafluoroethylene induced by proton irradiation. Mater. Des. 85, 162-168 (2015).

53. Li, J. et al. Novel ternary composites reduced-graphene oxide/zine oxide/poly (p-phenylenediamine) for supercapacitor: synthesis and properties. J. Alloy. Compd. 708, 787-795 (2017).

54. Wang, C. C., Wang, L. B., Li, F. J., Cheng, F. Y. \& Chen, J. Bulk bismuth as a high-capacity and ultralong cycle-life anode for sodium-ion batteries by coupling with glyme-based electrolytes. Adv. Mater. 29, 1702212 (2017).

55. Seh, Z. W., Sun, J., Sun, Y. M. \& Cui, Y. A highly reversible room-temperature sodium metal anode. ACS Cent. Sci. 1, 449-455 (2015).
56. Palchan, I., Crespin, M., Estrade-Szwarckopf, H. \& Rousseau, B. Graphite fluorides: an XPS study of a new type of C-F bonding. Chem. Phys. Lett. 157, 321-327 (1989)

57. Jiang, Y. et al. Highly reversible $\mathrm{Na}$ storage in $\mathrm{Na}_{3} \mathrm{~V}_{2}\left(\mathrm{PO}_{4}\right)_{3}$ by optimizing nanostructure and rational surface engineering. Adv. Energy Mater. 8, 1800068 (2018).

\section{Acknowledgements}

This work was supported by the National Key Research Program (No. 2018YFB0905400), National Natural Science Foundation of China (Nos. 51672156, 51622210, 51872277, and 51802361), Local Innovative Research Teams Project of Guangdong Pearl River Talents Program (No. 2017BT01N111), Guangdong special support program (2015TQ01N401), Guangdong Province Technical Plan Project (2017B010119001 and 2017B090907005), Shenzhen Technical Plan Project (JCYJ20170412170706047, JCYJ20170307153806471, and JCYJ20170817161221958), the DNL cooperation Fund, CAS (DNL180310). This work was also supported by the U.S. Department of Energy (DOE), Office of Energy Efficiency and Renewable Energy, Vehicle Technologies Office. Argonne National Laboratory is operated for DOE Office of Science by UChicago Argonne, LLC, under contract number DE-AC02-06CH11357. The authors gratefully acknowledge the Materials and Devices Testing Center of Tsinghua Shenzhen International Graduate School, Tsinghua University.

\section{Author contributions}

Y.-B.H., D.N.L., J.L., and F.Y.K. conceived the project. F.Y.K., Y.-B.H., J.L., Y. Yu and Y. Yang supervised the project and D.N.L., Y.-B.H., G.M.Z., Y. Yu and J.L. designed the experiments. D.N.L. performed the experiments with the help from G.M.Z., Q.Z., X.G.H., D.F.Z., J.B.M., Y.P.W., Q.P.Y., Y.Y. and Y.-B.H.; H.J.H. prepared the $\mathrm{Na}_{3} \mathrm{~V}_{2}\left(\mathrm{PO}_{4}\right)_{3}$ cathode material. C.L. and S.W.Z. completed the computational work. Y.-B.H., D.N.L., Y. Yu., J.L., G.M.Z., W.L., B.H.L., Q.-H.Y., Y. Yang and F.Y.K. discussed the results. D.N.L., Y.-B.H., J.L., Y. Yu and F.Y.K. wrote the initial paper which was approved by all the authors.

\section{Additional information}

Supplementary Information accompanies this paper at https://doi.org/10.1038/s41467 019-11960-w.

Competing interests: The authors declare no competing interests.

Reprints and permission information is available online at http://npg.nature.com/ reprintsandpermissions/

Peer review information Nature Communications thanks Hee-Tak Kim, Jong Hyeok Park, and other anonymous reviewer(s) for their contribution to the peer review of this work.

Publisher's note Springer Nature remains neutral with regard to jurisdictional claims in published maps and institutional affiliations.

\begin{abstract}
(c) (i) Open Access This article is licensed under a Creative Commons Attribution 4.0 International License, which permits use, sharing, adaptation, distribution and reproduction in any medium or format, as long as you give appropriate credit to the original author(s) and the source, provide a link to the Creative Commons license, and indicate if changes were made. The images or other third party material in this article are included in the article's Creative Commons license, unless indicated otherwise in a credit line to the material. If material is not included in the article's Creative Commons license and your intended use is not permitted by statutory regulation or exceeds the permitted use, you will need to obtain permission directly from the copyright holder. To view a copy of this license, visit http://creativecommons.org/ licenses/by/4.0/.
\end{abstract}

This is a U.S. government work and not under copyright protection in the US; foreign copyright protection may apply 2019 